\title{
Artículos
}

\section{Alejandría, una ciudad neoliberal: ultraconcentración, invasión pausada, división social simbólica y franquicias}

\section{Alexandria, a neoliberal city: ultra-concentration, quiet encroachment, symbolic social division and franchises}

\author{
María José Vizcaíno Pina* \\ Pedro Antonio Vizcaíno Pina**
}

\section{Resumen}

En Alejandría, Egipto, se ha producido un intenso proceso de "destrucción creativa" en un entorno que sufre los problemas consecuentes de la ultraconcentración en ascenso, agravado por la inexistencia de una planificación estatal coherente. El crecimiento sin planificación es evidente tanto en la "invasión pausada" que los ciudadanos adoptan en las calles de la ciudad, como en el decadente estado del espacio público. Según nuestro estudio, el desarrollo urbanístico de la ciudad se configura acorde a una división social simbólica que opone la ciudad cultural a la ciudad consumista elitista, siendo las franquicias de comida rápida símbolos del neoliberalismo urbano.

Palabras clave: ciudad neoliberal; Alejandría; invasión pausada; ultraconcentración; franquicias neoliberales; Egipto; urbanismo.

\footnotetext{
Abstract

The current map of the Egyptian Alexandria enables us to explain the neoliberal urban planning process. In the city occurs an intensive process of creative destruction in an environment that suffers the consequent problems of rising ultra-concentration,

* Antropóloga e investigadora independiente, Lisboa, Portugal. Correo electrónico: mariajosevizcainopina@gmail.com

** Doctorando de Sociología en la Universidad de Alejandría, Egipto. Dirección postal: Qesm Bab Sharqi, Alexandria Governorate, Egipto. Correo electrónico: pedrovizcainopina@ gmail.com

Nota de los autores: Este proyecto ha sido financiado por la Comisión Europea. El artículo refleja la opinión de los autores, y la Comisión no es responsable del uso que pueda hacerse de la información que contiene.
} 
aggravated by a lack of a coherent state planning. Urban development without planning is visible in the "quiet encroachment" process that citizens develop in the streets and in the decadent condition of the public space. According to our research, Alexandrian urban planning development is made under a symbolic social division that opposes the cultural city to the elite consumerist city. Fast-food franchises are distinctive symbols of urban neoliberalism.

Keywords: neoliberal city; Alexandria; quiet encroachment; ultra-concentration; neoliberal franchises; Egypt; urban planning.

\section{Introducción}

La urbanización es un proceso dentro del capitalismo, como señala Harvey (2016), y más específicamente todavía, “el capital se representa a sí mismo en la forma de un paisaje material creado a su propia imagen, creado como valor de uso con el fin de aumentar la progresiva acumulación de capital” (Harvey, 1978: 124).

En la época neoliberal, tanto en los países desarrollados como en los del sur global, el proceso de urbanización y especulación inmobiliaria es uno de los pilares de su crecimiento y beneficio, pero también gran generador de severas crisis. Ya en 1978, Topalov llegaba a una conclusión similar: la ciudad como el resultado de los procesos de urbanización capitalista, "la urbanización capitalista es, ante todo, una multitud de procesos privados de apropiación del espacio" (Topalov, 2006: 9). Esta premisa fue uno de los cuestionamientos que la sociología francesa empezó a considerar desde los años sesenta: la ciudad no existe a priori "como una realidad dada", sino que es fruto, como espacio generalizado, del capitalismo urbanístico. Este proceso se acelera en la época neoliberal en algunos países periféricos por su situación de dependencia en un sistema-mundo desigual, y por el abandono del Estado de su labor como fuerza equilibradora de las desigualdades sociales. La ciudad de índole capitalista en los países del sur global sigue el mismo patrón que en los países del norte, aunque con problemáticas diferenciadas.

Tres momentos fundamentales de la historia egipcia tienen una influencia clave para entender el urbanismo actual en Alejandría: primero, el país forma parte del sistema globalizado desde su época colonial europea (18821952) de exportación de materias primas e importación de manufacturas. En segundo lugar, tras la Revolución de 1952 y especialmente tras la Guerra del Canal de Suez de 1956, la mayor parte de la población expatriada comenzó a abandonar la ciudad, proceso que se destaca porque en esa época la mayoría de los negocios y el comercio estaban en manos extranjeras. Además, el 
gobierno avanzaba en el proceso de nacionalizaciones. En tercer lugar, Egipto inició sus políticas neoliberales desde el proceso de apertura -infitahdel presidente Sadat a mediados de los años setenta. Fue un periodo de crecimiento económico y, también, de aumento de la corrupción asociada al incremento de los ingresos públicos (Galal Amin, 2011:37). El país se aprovechó del boom del petróleo hasta bien entrada la década de los ochenta; sin embargo, tras la crisis posterior, el gobierno de Mubarak acabó por aceptar las políticas neoliberales del FMI para modificar su economía debido a la acumulación de una deuda externa insostenible. Fue la época del "estado blando" (Myrdal, 1979), la corrupción se institucionalizó, se limitó la fuerza de la ley, se privatizaron múltiples empresas públicas, y la inversión estatal en servicios públicos descendió (Galal Amin, 2011).

\section{Descripción geográfica de Alejandría}

En este artículo nos centramos en algunas de las características de la ciudad neoliberal de Alejandría, visibles por diversos motivos. En primer lugar, porque aunque tiene una especificidad propia, los efectos de este tipo de urbanización son claramente observables en la ciudad. En segundo lugar, la mayoría de los estudios urbanísticos sobre Egipto están centrados en El Cairo. ${ }^{1} \mathrm{Y}$ en tercer lugar, las características de la ciudad actual permiten entender su desarrollo urbanístico en las últimas décadas.

Alejandría, entendida como ciudad colonial -otomana primero y después bajo el dominio británico-, tuvo una influencia clave como puerto comercial importante durante el siglo XIX e inicio del XX por el hecho de ser una de las urbes que concentró la industrialización de esa época, debiendo gran parte de su protagonismo a su situación geográfica (Chaichian, 1988: 33; Ibrahim, 1975: 33).

La ciudad de Alejandría está situada en el Mediterráneo Oriental, en el extremo occidental del fértil delta del Nilo, en contraste con el sureste desértico. Está formada por una franja rectangular prácticamente regular, cuya urbanización histórica se desarrolla desde el suroeste hacia el noreste. El asentamiento moderno inicial es la ciudad otomana que se desarrolló alrededor del Puerto Occidental, hoy el actual puerto marítimo. Aunque podría corresponder con la descripción de ciudad islámica de desarrollo en parale-

${ }^{1}$ Las publicaciones del blog Cairo Observer (cairoobserver.com) y el libro Cairo Cosmopolitan: Politics, culture, and urban space in the new globalized Middle East (Singerman y Amar, 2006) son algunos ejemplos del interés que los estudios urbanos están suscitando en Egipto, aunque focalizados mayoritariamente en El Cairo. 
lo de Pelletier y Delfante (1997: 208), creemos que es más exacto considerar a Alejandría como colonial porque es en la época en la que se planifica y crece, y posteriormente seguirá la inercia de esta planificación. De hecho, la mezquita, que es clave en los modelos de ciudad islámica, ocupa en Alejandría un espacio secundario: la mayoría de las mezquitas que existen son de pequeño tamaño y las dos más importantes, Qa'id Ibrahim (1948-1951) y Abu al-Abbas al-Mursi (1928-1944), fueron construidas a mediados del siglo XX por el italiano Mario Rossi, en paralelo a la Corniche - paseo marítimopor tratarse del mejor escenario para reislamizar el urbanismo de la ciudad (Pallini, 2005: 194) (véase el Mapa 1).

La época colonial británica supuso la urbanización atomizada hacia el noreste de la ciudad. A partir de 1919 comenzó a realizarse el planeamiento urbanístico moderno de la urbe a través de un plan de comunicación y redes que permitiría la conexión de las diferentes partes de la ciudad hasta ese momento aisladas (Pallini, 2013: 193). De esta época datan algunas de las construcciones simbólicas de la ciudad en el periodo colonial británico. Este plan tiene su punto de origen en el Puerto Oriental.

\section{Mapa 1}

Alejandría con algunos de sus puntos simbólicos

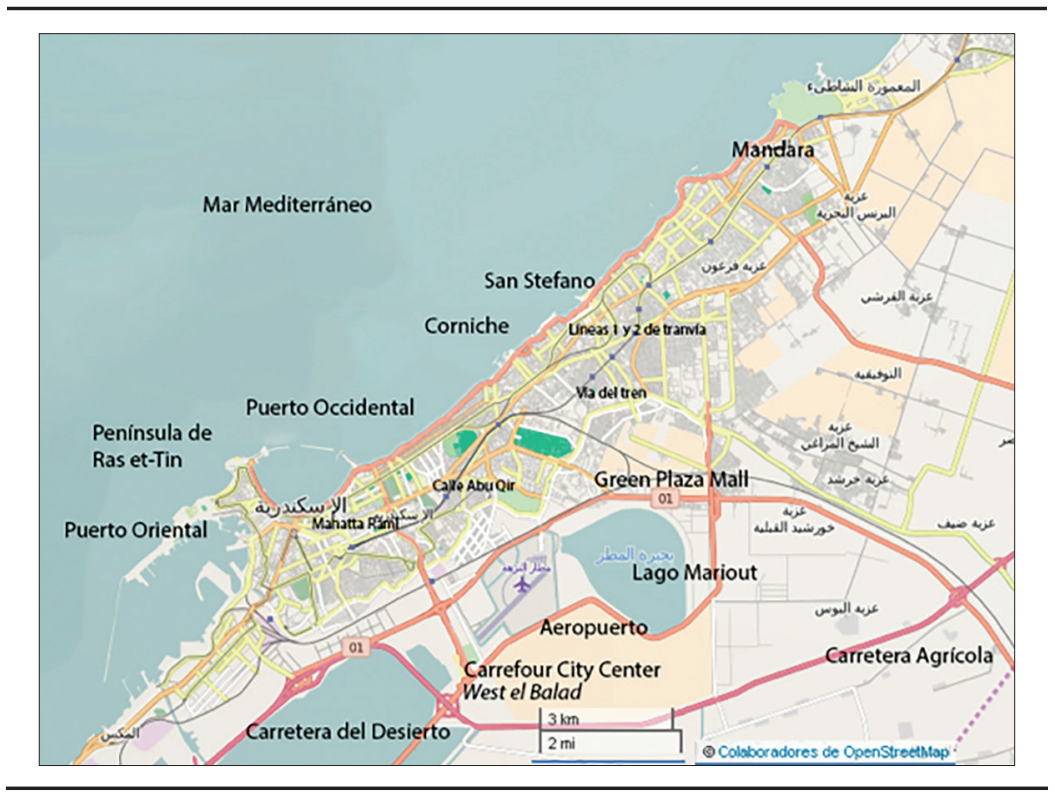

Fuente: Elaboración propia con base en OpenStreetMap. 
La pequeña península de Ras el-Tin, en cuyos extremos se sitúan los dos puertos primigenios -el Occidental y el Oriental-, se puede considerar, todavía hoy, el extremo occidental de la ciudad. Hacia el noroeste, el límite fuertemente marcado es el mar Mediterráneo, al lado del cual discurre la Corniche como red principal de comunicación de la urbe junto a la calle Abu Qir, que circula en paralelo a la Corniche pero por la parte central de la ciudad. Las otras redes básicas son las líneas de tranvía 1 y 2 y la línea de ferrocarril hasta Abu Qir, ambas prácticamente en paralelo también. El límite oriental de la metrópoli es más difuso y se encuentra en continuo desarrollo sobre las tierras fértiles del delta, pero se podría situar en la ciudad de Mandara, convertida en un barrio más de Alejandría. Al sur, el límite es la red de carreteras que administran el tráfico a las dos autovías que se dirigen a El Cairo (Carretera del Desierto y Agrícola), el aeropuerto, el lago Mariout y el Carrefour City Center.

Los diversos periodos históricos han dejado su huella en Alejandría. En este sentido, hay que tener en cuenta las diferentes fases de urbanización que tienen influencia en la ciudad actual: la época otomana, la fase colonial británica de desarrollo aislado y la siguiente de planificación, que intenta organizar la ciudad desde 1919. Posteriormente, las diversas fases desde la independencia.

A pesar de que las desigualdades urbanas son mucho más marcadas en El Cairo, Alejandría presenta una visible diferenciación social urbana entre los ganadores y perdedores de la globalización. ${ }^{2}$ Algunos de los aspectos urbanos que caracterizan actualmente a Alejandría como una ciudad neoliberal y que analizamos en la investigación son: la propia lógica de la ciudad capitalista neoliberal, la ultraconcentración, la ocupación privada del espacio público y la división simbólica de la urbe entre "ciudad cultural" y "ciudad consumista elitista".

2 Esta división es una de las principales características de la ciudad neoliberal en general, pero muy marcada en los países periféricos. Por las propias limitaciones de espacio no podemos centrarnos en este aspecto en el presente artículo. Sin embargo, nos interesa resaltar que en la ciudad se ha producido a lo largo del tiempo un proceso de suburbanización, desinversión y abandono del centro colonial, ultraconcentración en algunos barrios y descenso de la población en otros, división espacial por renta, pero también una combinación de habitantes con muy diversas rentas que viven en espacios contiguos por la importancia que todavía tienen en Egipto los servicios que las clases bajas prestan a las clases altas. Trabajamos en un artículo que explique la división social de la ciudad de Alejandría, intentando equilibrar el análisis entre consumo y producción (análisis crítico desarrollado en Smith, 2012). Por su complejidad hemos preferido diferenciar esta característica y dedicarle un espacio específico posteriormente. 


\section{Rasgos generales de la ciudad neoliberal}

El neoliberalismo no es un concepto lábil o polisémico (Rodríguez y Rodríguez, 2012), sino que se define por dos características retroalimentadas que determinan su unicidad histórica a nivel global: desmantelamiento del Estado de bienestar keynesiano (destrucción) en favor de una reestructuración social, política y económica (creación) que promueva la ganancia del sector privado; es lo que Harvey (2007) llamó "destrucción creativa". En contra del postulado que declara al neoliberalismo como un mecanismo que funciona sin ningún marco regulador, como un libre mercado, en la práctica, "el neoliberalismo realmente existente" (Brenner, Peck y Theodore, 2015) sólo puede existir y propagarse ayudado por las instituciones estatales o supraestatales fragilizadas en cuanto entidades distribuidoras de riqueza, pero fortalecidas en lo referente al control de las decisiones que fomenten el beneficio privado.

El proceso neoliberal ha tenido historias y dinámicas complejas en las diferentes áreas geográficas donde se ha ido imponiendo, apoyado en los múltiples espacios de dominio social, económico, político, medioambiental y urbano. Este último, el espacio urbano, ha ido adquiriendo un rol director de producción y reproducción del modelo neoliberal, por ser las ciudades espacios donde se concentran, cada vez más, los proyectos políticos y experiencias neoliberales, y donde se invierte una parte importante de la plusvalía en el continuo discurrir capitalista de la búsqueda del beneficio (Harvey, 1977: 248); es decir, durante las últimas tres décadas se ha producido "una marcada urbanización neoliberal" (Brenner et al., 2015: 239). Son numerosos los autores que han trabajado sobre la ciudad neoliberal (Harvey, 2007; Soja, 2008; Rodríguez, 2009; Carrión, 2016), pudiéndose enumerar un listado de características que reúne la ciudad neoliberal global actual.

Las apropiaciones privadas -en plural- del espacio público conforman una de las características fundamentales de la ciudad neoliberal, con el uso y abuso del espacio público que tiene su origen en el abandono estatal y en su posterior "invasión pausada" por parte de la ciudadanía. En segundo lugar, y aunque no es un rasgo que nace exclusivamente con la ciudad neoliberal, la división social simbólica de la metrópoli entre ciudad cultural versus ciudad consumista elitista. En tercer lugar, la ultraconcentración se ha convertido en un rasgo fundamental del neoliberalismo urbano. Por último, otro de los rasgos más llamativos y simbólicos del neoliberalismo global urbano lo representan las franquicias de marcas internacionales, como es el ejemplo paradigmático de McDonald's. La acumulación por desposesión (Harvey, 2007), la urbe como espacio de mercado que se impone sobre la urbe como 
comunidad política (Carrión, 2016), la prioridad de la ganancia sobre lo humano (vemos en Alejandría, por ejemplo, la escasez de parques para el bienestar social), los procesos de gentrificación y el abandono estatal del patrimonio histórico, son también rasgos de la ciudad neoliberal, que si bien no serán abordados extensamente en este trabajo, se incluyen referencias a éstos como elementos adheridos al análisis de su división social.

\subsection{Alejandría, una ciudad neoliberal}

Michael Janochska (2016) en una reciente ponencia sobre el derecho a la ciudad se preguntaba "¿cuál es el problema actual que padecen nuestras ciudades?", dando como respuesta inmediata "el capitalismo neoliberaldepredador". Alejandría se incluye dentro de este paradigma neoliberal que no es exclusivo de Occidente. A continuación desarrollamos algunas de sus características neoliberales más notorias.

\section{Ultraconcentración de población en Alejandría}

La concentración poblacional en Egipto es una cuestión histórica. De acuerdo con la Central Agency for Public Mobilization and Statistics (CAPMAS, 2016), únicamente el $7.8 \%$ del territorio del país está habitado y la mayoría de los habitantes se concentra en las inmediaciones del Nilo. Sin embargo, con el gran aumento de la población desde la Revolución de $1952,{ }^{3}$ la densidad ha crecido sustancialmente hasta las 89.2 personas $/ \mathrm{km}^{2}$, con un crecimiento de dos puntos anuales de media en los últimos diez años. ${ }^{4}$ En Alejandría, además, se añaden las propias limitaciones geográficas del Mar Mediterráneo al noroeste y el lago Mariout al sur. La población de Alejandría era de 4358439 en 2014, según datos de la ONU (2015), y la población total de la gobernación de Alejandría era de 4901910 habitantes. ${ }^{5}$

${ }^{3}$ En el censo de 1947 la población egipcia era de 18967 000; en el de 1960, después de la Revolución de 1952, ascendió a 26085000 (CAPMAS, 2016).

${ }^{4}$ En 2006 la densidad de población en Egipto era de 71.5 personas por $\mathrm{km}^{2}$; a inicios de 2016 había aumentado hasta los 89.2 habs. $/ \mathrm{km}^{2}$ (CAPMAS, 2016).

5 La gobernación de Alejandría reúne básicamente a la propia ciudad de Alejandría y a las ciudades suburbio de Abu Qir, Agami, Borg el Arab y Nueva Borg el Arab. La población de la gobernación aumenta alrededor de cien mil personas al año, por lo que teniendo en cuenta los datos de CAPMAS, la gobernación de Alejandría tendría actualmente unos 4.5 millones. No hay datos oficiales de la población de la ciudad específicamente. 
De hecho, existe un debate antiguo de si el problema de Egipto es de sobreurbanización (Davis y Golden, 1954), ultraconcentración de la población o alta densidad (Abu-Lughod, 1965: 315; Henderson, 2002: 89). La ultraconcentración supone alta densidad poblacional, pero también inadecuada gestión de residuos, tráfico denso, inexistencia de alojamiento adecuado a precios asequibles, contaminación, catástrofes naturales prevenibles y en general una ineficiente gestión de la ciudad. Es una problemática observable en las grandes ciudades egipcias, pero también en las ciudades medianas, que son las que más han crecido en las últimas décadas (Bayat y Denis, 2000: 187). El 72.8\% del territorio de la gobernación de Alejandría está habitado y de éste el $98.7 \%$ se considera urbanizado, siendo la densidad total de la gobernación de $28965 \mathrm{hab} / \mathrm{km}^{2}$ (CAPMAS, 2015). Esto conlleva ciertos problemas en lo que respecta a la planificación y la gestión de recursos. Ambas realidades -concentración y urbanización- están totalmente relacionadas en la actualidad en el medio urbano egipcio.

Según nuestro estudio, en Alejandría se produce una problemática clara de ultraconcentración en ascenso, siendo la presencia de ashwaiyyat, o barrios informales, residual en comparación con El Cairo, aunque continúa existiendo un déficit importante de vivienda a precio asequible para quienes perciben ingresos bajos.

El urbanismo actual de Alejandría se puede entender como un proceso continuista de inercia de la planificación colonial de desarrollo hacia el noreste de la ciudad. La planificación de las autoridades egipcias en las últimas décadas se ha centrado en la creación de ciudades satélites, atrayendo fábricas e intentando hacer lo mismo con la población, pero ha tenido un éxito limitado (Tarbush, 2012: 178-179), olvidándose por completo de la planificación en las grandes ciudades existentes.

La ultraconcentración en Alejandría presenta importantes problemas, como hemos señalado anteriormente, pero también aspectos positivos para una población resiliente a ellos. En lo que respecta a los problemas, supone deficiencias en la gestión de residuos -los contenedores de basura suelen ser insuficientes, rebosan de basura y ésta es desparramada por personas que reciclan papel, cartón y plástico ya que no se recicla de forma oficial-, siendo la abandonada gestión por parte del Estado visible en cualquier ciudad egipcia, pero de un modo más extremo en Alejandría (Fotografía 1).

Otro de los problemas son las inundaciones que golpean a la ciudad en la época de mayores lluvias. Una red de drenaje incapaz de soportar la creciente densidad de población, las conexiones ilegales y un mantenimiento deficiente agravan dicha situación (Fotografía 2). 


\section{Fotografía 1}

Montón de basura en el barrio de Roushdy, uno de los barrios acomodados de la ciudad

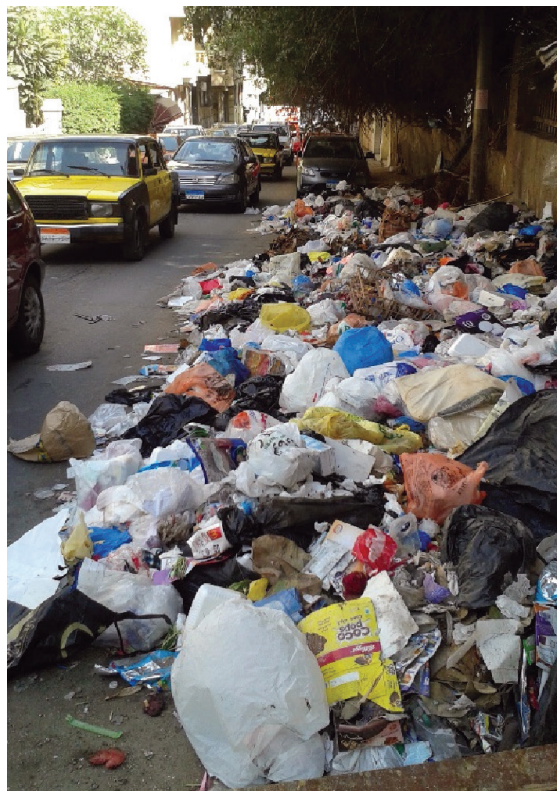

Fuente: Fotografía de los autores.

\section{Fotografía 2}

Calle principal de Agamy inundada en la época de lluvias

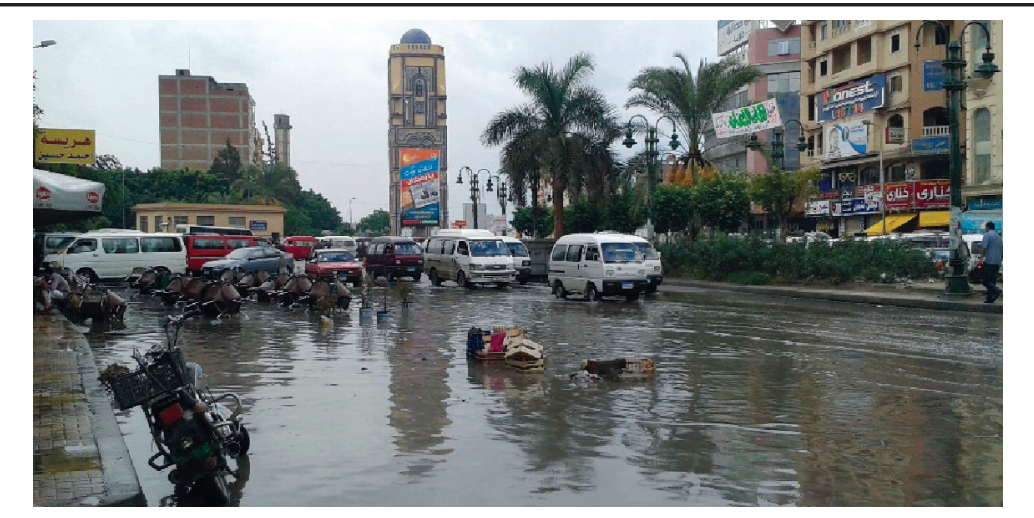

Fuente: Fotografía de los autores.

Estudios Demográficos y Urbanos, vol. 33, núm. 1 (97), 2018, pp. $43-78$ ISSN 0186-7210; e-ISSN 2448-6515; doi: http://dx.doi.org/10.24201/edu.v33i1.1734 
En lo que respecta a los aspectos positivos, como ha señalado Nada Tarbush (2012: 178) al comentar la realidad en El Cairo, la ultraconcentración supone beneficios relativos para sus habitantes: el apoyo social al tener a los conocidos cerca en caso de necesidad, el comercio es más fácil, y el transporte es más rápido y sencillo teniendo en cuenta las problemáticas existentes. En nuestra opinión, estos aspectos positivos están más relacionados con el apoyo familiar y social de las redes de conocidos y no tanto por la ultraconcentración.

\section{Uso y abuso del espacio público: la invasión privada}

El abandono estatal y el escaso aprovechamiento del espacio público por parte de la población, y por otra parte la invasión privada del espacio público que limita además las posibilidades de uso de éste, son dos características urbanas visibles en Alejandría.

El abandono estatal del espacio público se hace evidente en cualquier breve paseo por la ciudad. Las calles están sucias, numerosas aceras destruidas, la basura se acumula en múltiples lugares, los cascotes (escombros) de una obra antigua se amontonan donde se quedaron meses atrás y así sucesivamente; tales realidades están habitualmente relacionadas con el escaso mantenimiento de la ciudad, tanto público como privado. Además, para la mayoría de la población el espacio público no es de "nadie", por lo que tampoco se contribuye a su mantenimiento ni se exige a las autoridades que se mantenga (Fotografía 3).

La causa de esta situación lamentable es la propia lógica capitalista: olvido estatal hacia aquellos que "no aportan" al beneficio de la clase dirigente. David Harvey (2016) considera la crisis económica que vivimos -reflejada en las ciudades, podríamos añadir- como un "proyecto de clase", entiéndase, de la clase dominante. Algunas preguntas que surgen respecto al abuso y mal uso del espacio público serían: ¿por qué los ciudadanos sitúan sus pequeños negocios ambulantes en las aceras? Y ¿por qué se tira la basura en las calles? Es la de los ciudadanos, también, una visión capitalista: si no es mi propiedad, no importa. Pero, ¿cómo surge este imaginario social? ¿Es efecto o causa del abandono estatal? ¿Consideramos los ciudadanos "lo público" como algo nuestro, "propio"? Harvey (2016) nos habla también de cómo el "nuevo imperialismo" ha convertido en mercancía la mayoría de las prácticas culturales o naturales; así, sólo se valoriza aquello que tiene valor de mercado: la propiedad privada o el beneficio personal.

En este escenario neoliberal se ha ido desarrollando un proceso de “desposesión por acumulación” que lleva a que los espacios comunitarios o 


\section{Fotografía 3}

Calle Soter ocupada por talleres, aparcamientos en doble y triple fila, basura y demás objetos

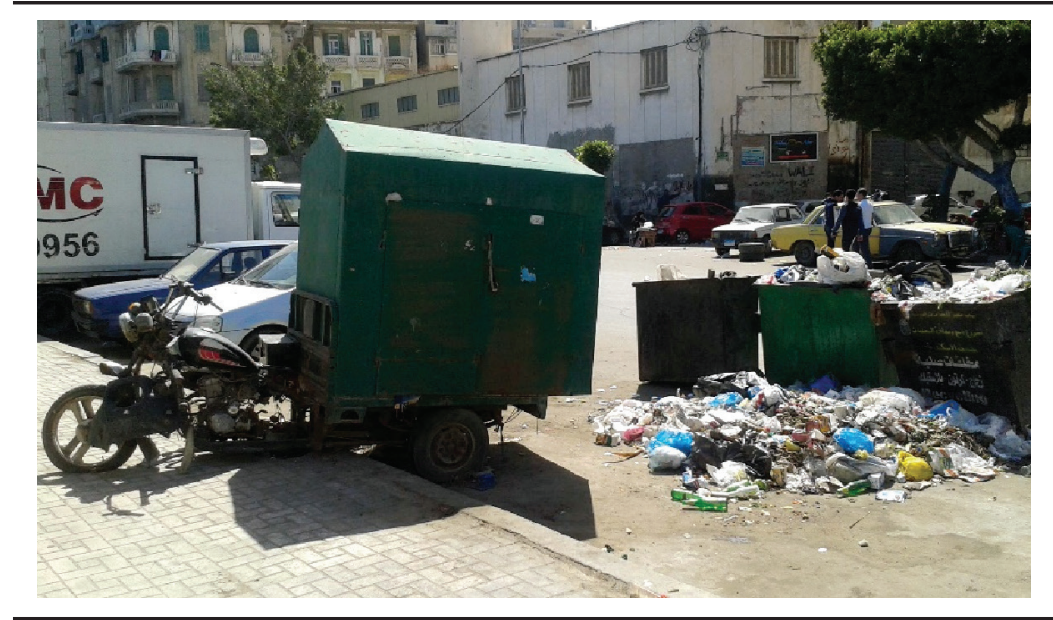

Fuente: Fotografía de los autores.

colectivos -es decir, "lo público"- sean vistos por los ciudadanos cada vez menos como propios, ya sea desde un punto de vista de identidad social o de propiedad en el sentido capitalista. De este modo, la ciudad va perdiendo su significación de comunidad política, donde lo público es propiedad del ciudadano, dirigiéndose hacia su mercantilización. Es decir, desemboca en la afirmación de que lo público se opone a lo privado (Carrión, 2016).

La ciudad egipcia neoliberal está adaptada para la movilidad en vehículo privado, al igual que como ocurre en la mayoría de los países; sin embargo, este proceso de transformación conlleva una problemática importante en Alejandría. El diseño colonial de la urbe contribuye a que desplazarse en coche sea más eficiente que en El Cairo, pero esto no evita que se observen los mismos problemas, aunque de forma limitada: la ciudad no es capaz de contener el parque móvil de coches; las normas de tráfico apenas se cumplen, contribuyendo al tráfico denso; las aceras están malogradas u ocupadas por múltiples objetos, como coches y basura, trasladando así a los peatones al espacio que queda entre los autos que circulan y los que están aparcados porque es el único lugar para caminar, con los evidentes peligros que esto conlleva, aunado al escaso respeto de los conductores hacia los transeúntes.

Además de lo anterior, existe un claro darwinismo social que depende del tamaño del medio de transporte utilizado: los coches tienen "prioridad 


\section{Fotografía 4}

Aceras destruidas en las inmediaciones del Puente de Stanley

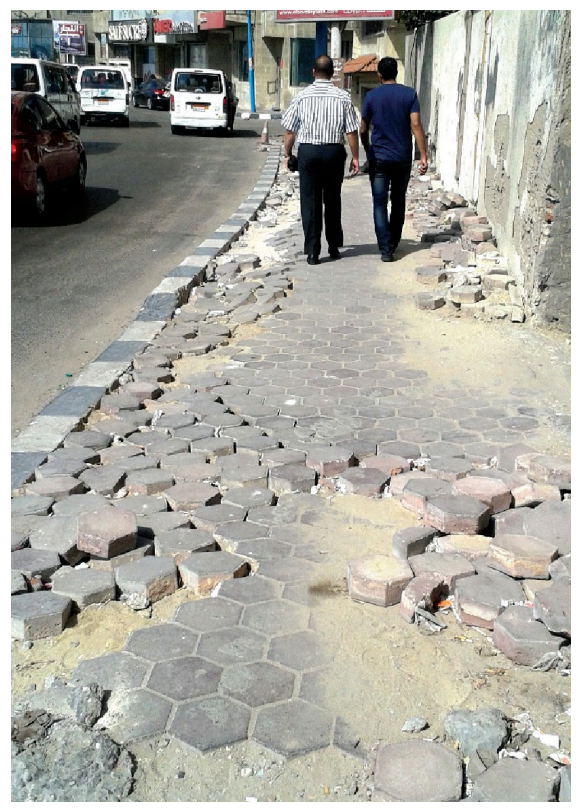

Fuente: Fotografía de los autores.

social" sobre los ciclistas, y ambos sobre los peatones. Con la excepción de algunas avenidas con aceras amplias -la Corniche-, no es sencillo caminar en la ciudad (Fotografía 4).

La ocupación privada del espacio público contribuye además a que la anterior situación se agrave. En Alejandría apenas existen espacios públicos para el uso gratuito de la población, y los pocos que existen están en condiciones bastante lamentables, lo cual influye en la creación de una clara división social entre quienes se pueden permitir visitar clubes sociales y deportivos, restaurantes caros o espacios de consumo privado y quienes no pueden acceder a ellos (Fotografía 5).

El espacio público se ocupa de múltiples formas: vendedores que sacan su mercancía a la calle, coches aparcados en la acera, inauguraciones de negocios, bodas, ceremonias fúnebres para las que se construye un recinto temporal en medio de la calle, puestos de guardia policiales, vallas y casi cualquier obstáculo imaginable que contribuye a limitar el espacio que podría disfrutar la población y, especialmente, los peatones (Fotografía 6). 


\section{Fotografía 5}

El parque Shalalat todavía más desarreglado después de unas canalizaciones subterráneas de agua

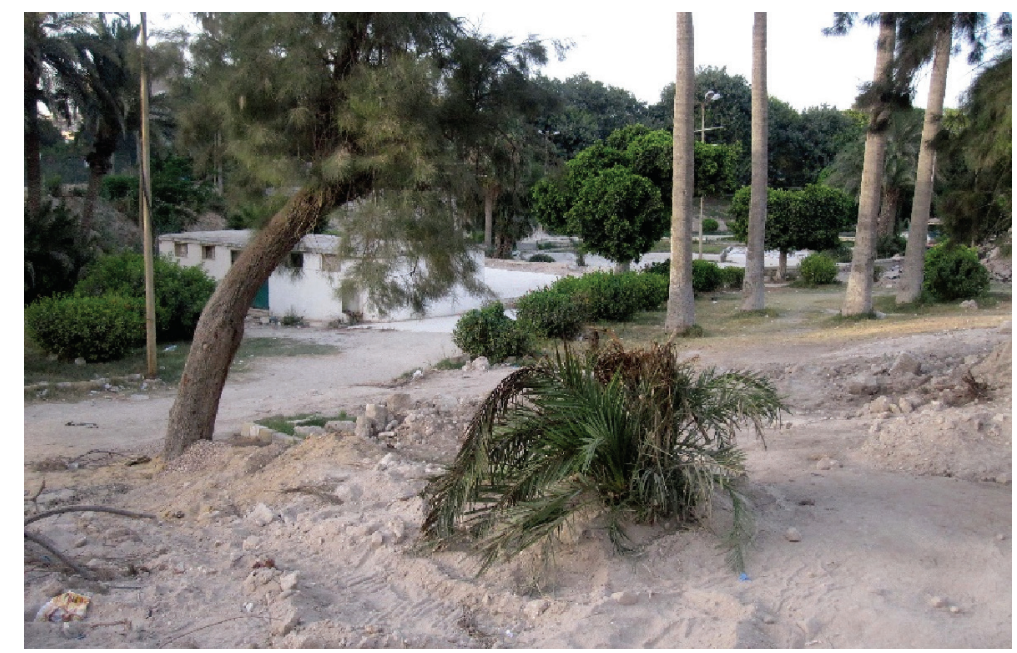

Fuente: Fotografía de los autores.

\section{Fotografía 6}

Vendedores callejeros de ropa en la calle Saad Zaghloul, en las inmediaciones del mercado de Mansheyya

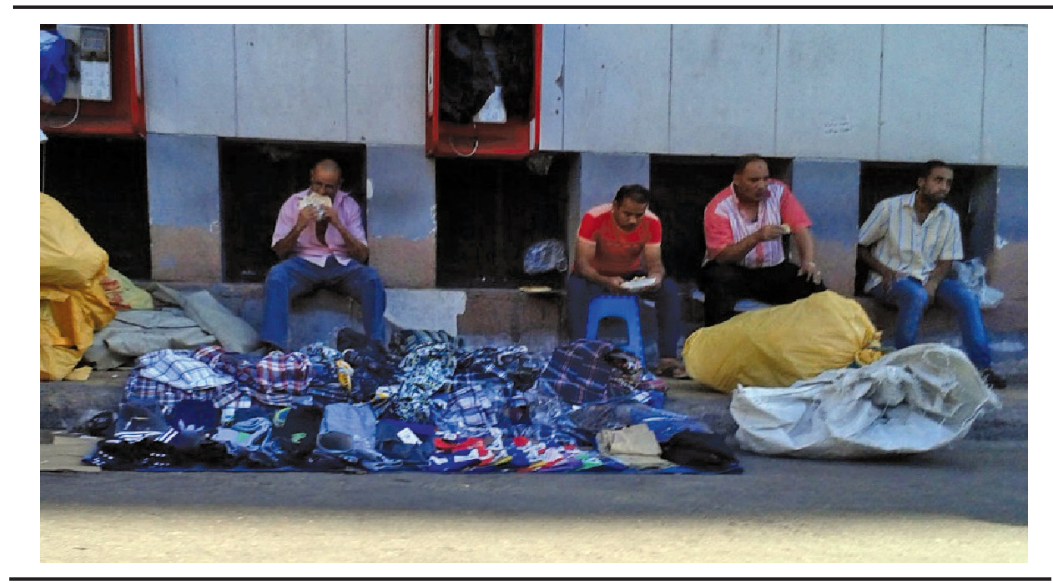

Fuente: Fotografía de los autores.

Estudios Demográficos y Urbanos, vol. 33, núm. 1 (97), 2018, pp. 43-78 ISSN 0186-7210; e-ISSN 2448-6515; doi: http://dx.doi.org/10.24201/edu.v33i1.1734 
Asef Bayat ha enriquecido el debate con el concepto de "invasión pausada" (quiet encroachment), haciendo referencia a

[...] las acciones no colectivas prolongadas y directas realizadas por individuos y familias de forma independiente para cubrir las necesidades básicas de su vida diaria (lugar para vivir, bienes y servicios urbanos de consumo, trabajo informal, oportunidades de trabajo o espacio público) de una forma pausada y sin pretensiones de realizar algo ilegal [Bayat, 2010: 45; traducción propia].

Como señala Bayat, esta realidad es visible en cualquier ciudad de los países periféricos ${ }^{6}$ (en menor medida en los países capitalistas centrales), siendo una de las características propias de la ciudad neoliberal. El contrato social se ha roto y se produce un proceso continuo de negociación entre la población y el Estado. Éste es incapaz de obtener impuestos de dichas actividades y ejercer su poder de control, pero a la vez le conviene ya que millones de personas obtienen sus ingresos de forma independiente sin exigir el apoyo estatal. Sin embargo, continuamente el Estado pretende controlar este movimiento, aunque es incapaz de hacerlo porque tampoco tiene nada que ofrecer para solucionar el problema.

Otra forma de ocupación privada del espacio público es la privatización de la costa de Alejandría; sin embargo, tal ocupación se presenta en un grado diferente al de la "invasión pausada", ya que en este proceso el acuerdo público-privado es claro: los más de 18 kilómetros de costa con los que cuenta Alejandría están privatizados, ${ }^{7}$ básicamente a través de cafés caros y playas comerciales; prácticamente no se puede disfrutar la costa de forma gratuita, salvo en algunos lugares de acceso libre (Fotografía 7).

Llegamos a la conclusión de que la ocupación temporal mercantil de espacios comunes es consecuencia de dos acciones capitalistas retroalimentadas entre sí. Por un lado, se prioriza la creación de "centros consumistas" rentables, despreocupándose del mantenimiento de los espacios públicos. Por otro lado, la carencia de infraestructura o su estado lamentable conduce a los ciudadanos a un uso del espacio común basándose en una tendencia neoliberal donde se prioriza el beneficio individual (por ejemplo, el mecá-

${ }^{6}$ Hacemos referencia a la teoría de centro-periferia desarrollada por economistas de la CEPAL tras la Segunda Guerra Mundial, ampliada a nivel global y de manera independiente por Wallerstein en su modelo sistema-mundo.

${ }^{7}$ El acceso a la playa de Maamura, cercana a Mandara, implica dos gastos mínimos: el pago de una entrada al barrio y la entrada a la playa; esta última cuesta 15 libras egipcias. Además, hay posibilidades de realizar gastos extras: alquiler de sillas, mesa y sombrilla. Sin embargo, ésta no es de las playas más caras. El acceso a la playa de San Stefano, uno de los centros consumistas elitistas, cuesta 400 libras egipcias. 


\section{Fotografía 7}

Playa de Bahary: es gratuita pero no goza de buena fama y está llena de cafés y de negocios de alquiler de sillas y sombrillas

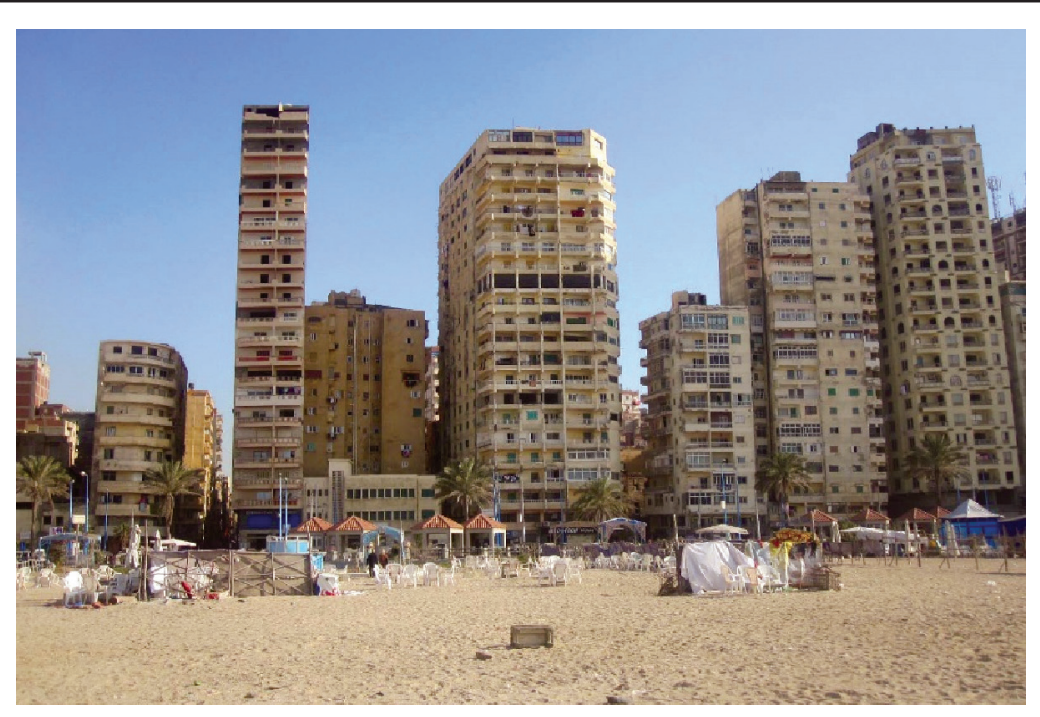

Fuente: Fotografía de los autores.

nico que repara coches en mitad de la calle) frente al bien común público (los peatones tendrán que esquivar los bultos del mecánico, soportar la suciedad, los ruidos). En ambas conductas sociales se produce un incumplimiento de las obligaciones políticas y/o cívicas. El Estado no contribuye a satisfacer las necesidades ciudadanas (aunque éstas no sean expresadas de modo directo - por ejemplo, a través de manifestaciones-, los poderes públicos deben, según su propia naturaleza representativa, cumplir las demandas de necesidades básicas). Los ciudadanos, sutilmente y sin protestas definidas ${ }^{8}$ se van apropiando de un espacio común. El resultado es la ineficiencia en el devenir urbano, donde las apropiaciones enteramente neoliberales y contrapuestas se retroalimentan en contra del paradigma del "derecho a la ciudad"; de este modo tiene lugar una división segmentaria y desaprovechada del espacio urbano.

${ }^{8}$ Bayat (2010) señala que los ciudadanos que "invaden pausadamente" sólo se manifestarán cuando las autoridades pretendan retirarlos del espacio invadido que ellos ya consideraban como suyo: el espacio público se habría convertido en privado. 


\section{División social simbólica de la urbe. La ciudad cultural y la ciudad consumista elitista}

En las ciudades neoliberales suelen existir fronteras territoriales como marcas de segregación urbana. No son un rasgo que nace específicamente con la ciudad neoliberal, sin embargo, este modelo de urbe se define por potenciar -ya sea directa o indirectamente- la separación espacial e "imaginaria" de los territorios urbanos. Santillán Cornejo (2015) hace un breve recorrido histórico sobre los análisis urbanísticos realizados en torno a la capital ecuatoriana: así, Quito continúa, a pesar de que materialmente las fronteras inamovibles de mediados del siglo XX se han diluido, dividida en el imaginario social entre un norte "pudiente" y un sur "desfavorecido". En Alejandría, del mismo modo, existe un "imaginario urbano" (Silva, 2004) dual en cuanto a la representación del centro de la ciudad.

En la Alejandría actual nos encontramos dos tipos de estos centros simbólicos, dependiendo de quién sea nuestro interlocutor. Históricamente y para la mayoría de la población alejandrina, el concepto de centro -West el-Balad, en árabe-se refiere a la parte histórica, situada al oeste de la ciudad, donde se concentran los edificios coloniales, una parte importante de los negocios, bancos, y sobre todo la mayoría de la actividad cultural de la ciudad. Las familias ricas mantuvieron sus residencias allí o, al menos, la propiedad de una parte importante de los edificios. Sin embargo, tanto la élite británica e internacional antes de la Revolución, como la egipcia tras la independencia, priorizó el proceso de suburbanización, trasladando la residencia principal a villas más amplias en el barrio de Kafr Abdou y posteriormente al barrio de Smouha, ya que, como ocurre en El Cairo (Tarbush, 2012), la parte histórica de la ciudad es considerada por la clase acomodada como caótica, sucia y contaminada (Mapa 2).

Así, "el centro" de la ciudad es Mahatta Raml para la mayoría de sus habitantes, y para una minoría es el complejo West-el Balad-Carrefour City Center, el Green Plaza Mall o el complejo de San Stefano, lo cual muestra claramente el simbolismo imaginario del centro. Alrededor de la estación de tranvía de Raml se desarrolló la urbe colonial y todavía es un lugar central de encuentro por su localización en lo que respecta a la ciudad cultural. La mayoría de los espacios culturales - tanto públicos como privados- se sitúan en la parte colonial: la Biblioteca de Alejandría, los centros culturales francés, alemán, español, ruso y griego, Terracina, L'Atelier, la asociación privada Gudrán y el Centro de la Libertad para la Creatividad (Mapa 3).

Para otra porción de la población, especialmente entre los nuevos ricos, el imaginario social (Silva, 2004) del centro de la ciudad, West el-Balad, se 


\section{Mapa 2}

Centros culturales y consumistas de Alejandría

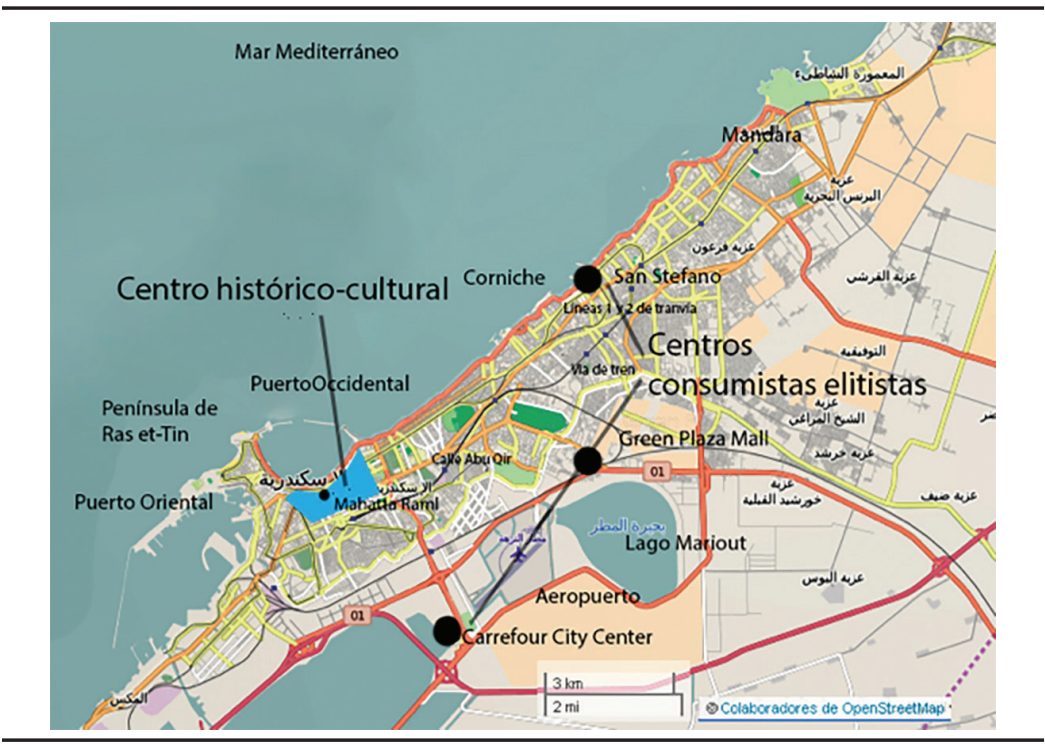

Fuente: Elaboración propia con base en OpenStreetMap.

\section{Mapa 3}

Espacios culturales en el centro histórico de Alejandría

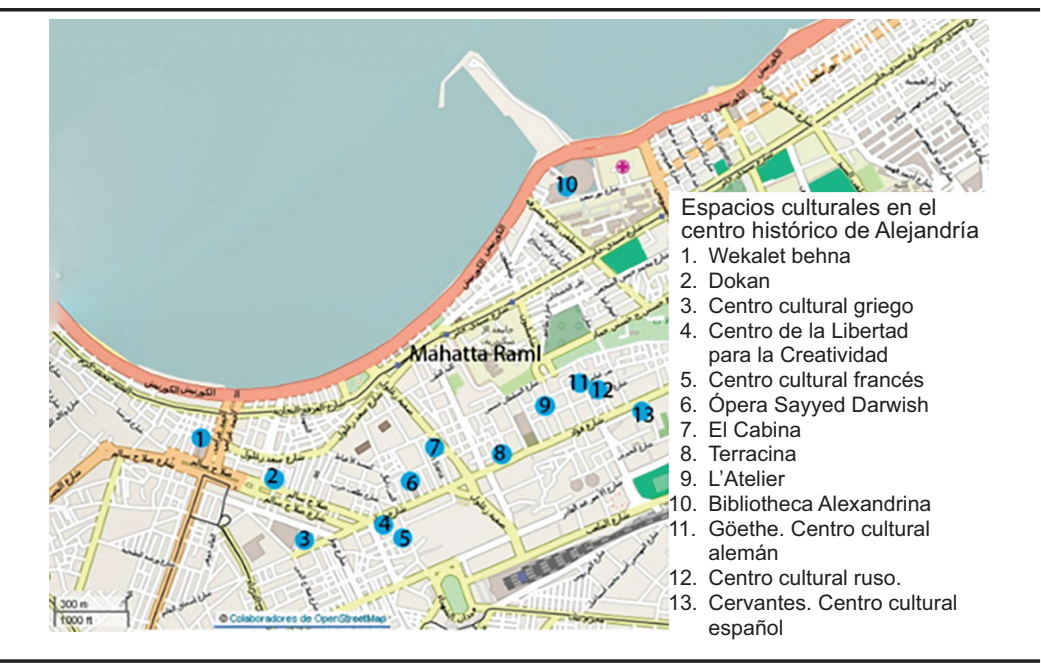

Fuente: Elaboración propia con base en OpenStreetMap.

Estudios Demográficos y Urbanos, vol. 33, núm. 1 (97), 2018, pp. $43-78$ ISSN 0186-7210; e-ISSN 2448-6515; doi: http://dx.doi.org/10.24201/edu.v33i1.1734 
ha trasladado simbólicamente hacia Carrefour City Center, Green Plaza Mall y San Stefano. Hemos denominado a estos "centros de la ciudad" como centros de consumo elitista. Se trata de modelos de consumo similares a los estadounidenses, adaptados en Dubai y exportados al mundo árabe (Elsheshtawy, 2006: 248).

El simbolismo entre los "centros" queda patente en la estrategia de marketing de los centros consumistas, ya que el complejo de ocio que se ha desarrollado alrededor del Carrefour City Center se llama West el-Balad (ambos con el adjetivo de "centro de la ciudad" añadido a su nombre en inglés y árabe, respectivamente), en un intento de traslado del centro simbólico hacia esta parte de la urbe dedicada esencialmente al consumo elitista, donde se ubica el citado centro comercial, restaurantes caros, zonas de ocio variadas y lugares de eventos, todos ellos con precios elevados.

La situación social de Green Plaza es similar, con el añadido de un hotel Hilton, de tamaño más limitado y con el rasgo distintivo de ofrecer sus servicios al creciente número de habitantes del barrio Smouha que, a pesar de ser una parte histórica de la ciudad, concentra el gran crecimiento residencial de renta media y alta de la metrópoli. El crecimiento de las zonas residenciales y centros consumistas elitistas en Alejandría está relacionado con la "inversión de prestigio" de vivir en los edificios más caros de Smouha. Evidentemente no sólo este aspecto interviene; hay que considerar que cuenta con las mejores comunicaciones, menor tráfico, mayor espacio para aparcar, así como la cercanía a los espacios de consumo elitista donde el coche es un elemento diferenciador respecto al consumismo popular del centro histórico.

En los límites del centro histórico también existe un espacio de consumo, el mercado de Mansheyya, un barrio de calles estrechas repleto de tiendas divididas según el tipo de producto, pero de un consumo popular muy alejado del elitismo de los centros consumistas anteriormente mencionados. Algunas calles del centro histórico que reúnen básicamente tiendas de ropa, como Saad Zaghloul, se ven además ocupadas por vendedores informales (Fotografía 8).

El tercero de los centros consumistas es San Stefano y, a diferencia de los anteriores, se desarrolla de forma absolutamente independiente del barrio circundante. Comprende un hotel Four Seasons, apartamentos, tiendas y franquicias dentro del propio complejo (Fotografía 9).

El uso del coche diferencia ambos tipos de consumo de forma evidente. Las zonas destinadas a las personas de renta alta dependen en gran medida del automóvil, ya que apenas existen transportes públicos que vayan a estos lugares, hay menos minibuses privados que conecten con las otras zonas de 


\section{Fotografía 8}

Apertura de las tiendas de ropa en el mercadillo de Mansheyya

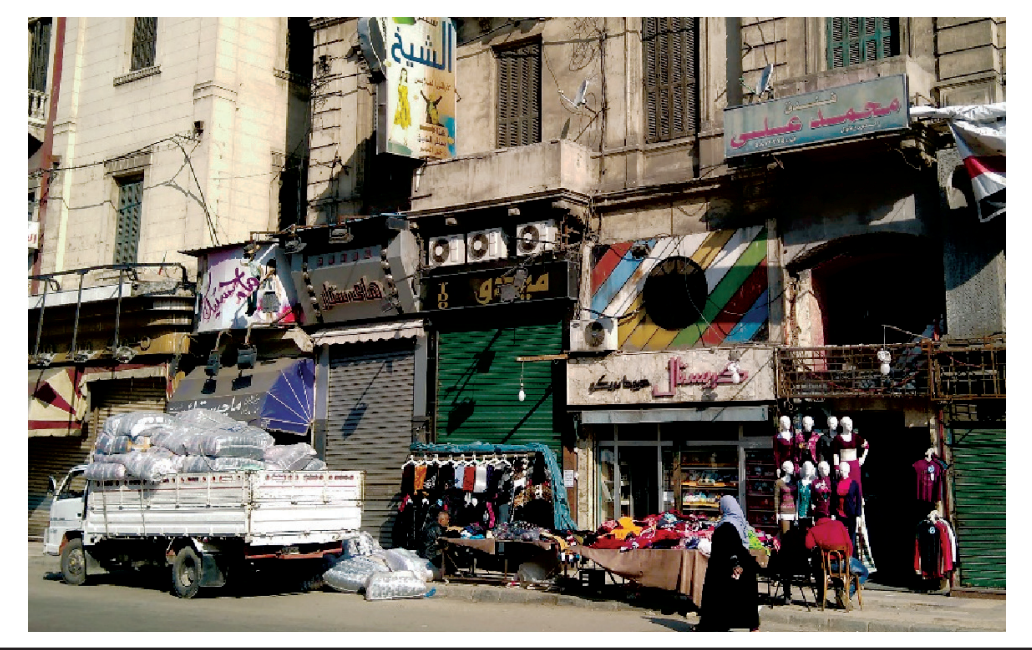

Fuente: Fotografía de los autores.

\section{Fotografía 9}

Complejo de ocio y consumo San Stefano, enfrente de la costa mediterránea

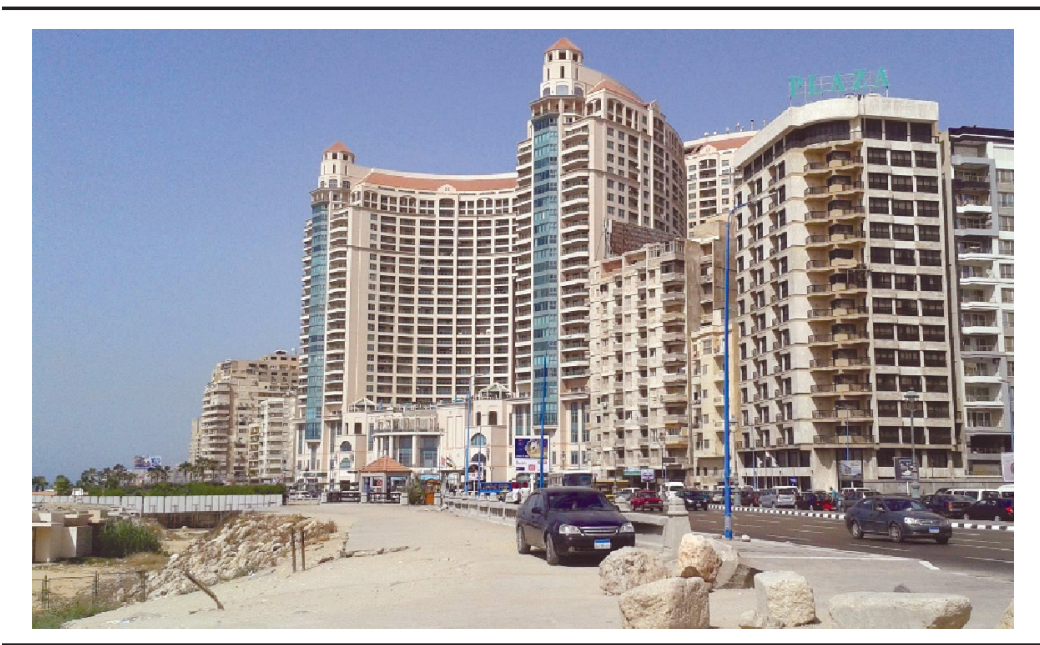

Fuente: Fotografía de los autores.

Estudios Demográficos y Urbanos, vol. 33, núm. 1 (97), 2018, pp. $43-78$ ISSN 0186-7210; e-ISSN 2448-6515; doi: http://dx.doi.org/10.24201/edu.v33i1.1734 
la ciudad y el espacio de aparcamiento es mayor. El centro histórico, sin embargo, está conectado con múltiples servicios de minibuses, por lo que cualquier persona puede llegar hasta esta parte de la urbe y pasear mientras pueden consumir de una forma mucho más económica. Aunque se puede llegar también en coche, los problemas de tráfico, el escaso espacio y la necesidad de pagar por aparcar convierten el uso del coche en el centro histórico más en un problema que en un medio rápido de transporte individual.

Una de las premisas en que el "neoliberalismo realmente existente" (Brenner et al., 2015: 230) se apoya es la regulación del desarrollo espacial desigual. Si de modo amplio la teoría del neoliberalismo realmente existente explica cómo funciona en la práctica el neoliberalismo, de modo específico la práctica del desarrollo espacial desigual confronta la destrucción del apoyo estatal a determinados espacios globales o zonas de la ciudad con la creación de nuevas políticas públicas para potenciar la movilidad del capital y así, consecuentemente, la polarización desigual de espacios. Se produce lo que Harvey (2007) llamó la destrucción creativa del neoliberalismo, un reajuste de las decisiones públicas que facilitan la mercantilización neoliberal. En Alejandría el proceso de destrucción creativa es llamativo en la construcción masiva de edificios y en el uso mercantil de la costa a través de cafeterías caras, clubes sociales y accesos a la playa mediante el pago de una entrada, poniendo de manifiesto la división social simbólica de la ciudad (Fotografía 10).

La transformación de la ciudad construida y la forma urbana (Brenner et al., 2015: 235) -en términos generales la eliminación de espacios públicos que favorece la creación de espacios nuevos elitistas- ha sido uno de los mecanismos de los que el urbanismo neoliberal se ha servido en ciudades de Europa occidental y Norteamérica para imponer sus principios sustentadores. Del mismo modo, este proceso de destrucción creativa impera en la ciudad neoliberal de Alejandría. El Carrefour City Center West el Balad es el enclave simbólico más llamativo de creación - espacios de consumo para élitesdestructiva -estas invenciones de espacios propios para una minoritaria parte de la población egipcia se hacen en detrimento de la conservación e inversión en infraestructura pública. 


\section{Fotografía 10}

Pequeño café en primera línea de playa con únicamente sillas, mesas y sombrillas

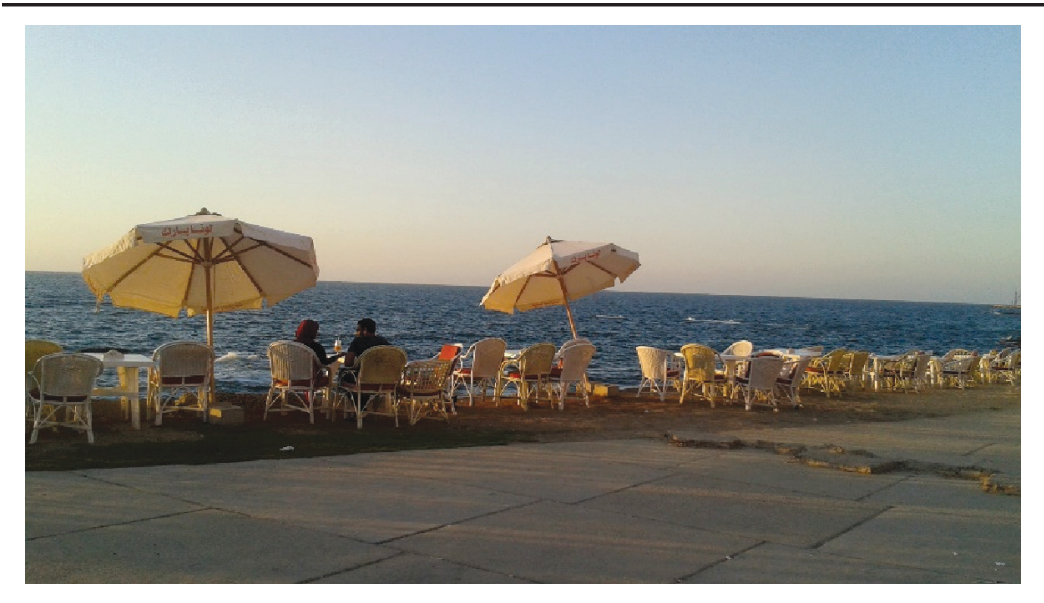

Fuente: Fotografía de los autores.

\subsection{La especificidad de Kafr Abdo: barrio histórico y centro de consumo elitista}

La segregación socioespacial de Alejandría que es hoy visible en la ciudad comienza más atrás en el tiempo que la reciente creación de los tres centros consumistas mencionados. Alejado del casco histórico surgió el barrio Kafr Abdo, área residencial conformada tanto por élites egipcias como por extranjeros (contrasta con el resto de la ciudad por la presencia de áreas con árboles, cafeterías y villas). Este barrio se llamó originalmente Marshall Allenby, en honor a un comisionario británico de Egipto nombrado en 1919, pero con la revolución de Nasser y el proceso de "egiptización" su nombre pasó a Kafr Abdo. El barrio continúa habitado por familias poderosas del mundo de los negocios, de la academia, profesionales y expatriados con altos salarios; sin embargo, las iniciativas constructoras han demolido - destrucción-muchas de las villas, construyendo edificios de pisos-creativa-sin estimar el valor arquitectónico y cultural que se pierde.

Kafr Abdo es, en la actualidad, el centro geográfico de Alejandría no oficial; sin embargo, el concepto de centralidad lo mantiene Raml. La complejidad de las ciudades actuales impide analizar las urbes en términos unívocos de centro versus periferia. Aldo Rossi (1971) señala que el rasgo 
definitorio del centro es cumplir un rol destacado y concreto para la vida urbana. Kafr Abdo cumple con el rasgo de centralidad geográfica -centro geométrico-, sin embargo, su carácter de centro como Rossi lo describe es problemático. En primer lugar, en Alejandría es necesario pensar la centralidad desvinculándola de su posicionamiento geográfico o geométrico. Kafr Abdo simboliza la contradicción urbana del concepto de centralidad. Por un lado, podría considerarse, por ser el hábitat urbano de la élite alejandrina y extranjera, como centralidad desde un punto de vista funcional y jerárquico; es el lugar donde viven las personas que detentan un rol decisivo en la imposición y continuación del modelo urbano neoliberal, encajando en el concepto de "lugar de centralidad" de Paris (2012: 49). Por otro lado, Kafr Abdo no es un lugar estructural con aglomeración de servicios administrativos, de comercio, de decisiones políticas -en forma de edificios gubernamentales, por ejemplo-, ni cumple con el clásico carácter de comunidad política que tuviera el ágora griega y que, recientemente, Carrión (2016) define como una de las ausencias características de la ciudad neoliberal. El barrio de Kafr Abdo surgió durante el dominio británico y acumula dos rasgos fuertemente simbólicos: antigüedad y elitismo. Su pervivencia como residencia de la élite le dota de una vigencia actual como espacio jerarquizado social y económicamente; además, este barrio suma como característica aquello que Brenner et al. (2015: 235) llamaron "comunidades cerradas" (gated communities), que facilitan la reproducción social.

Kafr Abdo combina diversos aspectos que lo hacen específico: zona residencial elitista que ha mantenido su posicionamiento a pesar de la construcción de otras zonas para la clase alta, zona de consumo local con restaurantes y cafés caros en el propio barrio, y una historia -aunque únicamente residencial- que le permite mantenerse como barrio de la clase alta, a pesar de que ahora existen otros barrios con esta consideración, básicamente en áreas de Smouha.

Alejandría adopta el esquema de las ciudades contemporáneas donde se abandona la exclusividad de un centro en favor de la dispersión de lugares de centralidad. Mahatta Raml, así como Kafr Abdo, no se definen por el mismo valor de centralidad: el primero es un centro tradicional consolidado con un papel importante como configurador de las actividades culturales y de reunión para una amplia parte de la población. Kafr Abdo, en cambio, a pesar de no ser un centro en el sentido tradicional de Rossi (1971), figura como centralidad y comunidad cerrada frente a la periferia; esta vez, centro versus periferia definidos en términos de poder adquisitivo y jerarquía social. Y es que "las funciones centrales en el entorno ya no dependen del simple valor posicional, sino que lo hacen del valor de centralidad origina- 
do por la interacción entre las personas y los espacios de estas funciones" (Paris, 2012: 57).

Es decir, se observa en Alejandría cómo la difusión de los centros y de la centralidad, su carácter policéntrico, permite explicar en la actualidad la historia urbanística y la división social en el terreno. Si Kafr Abdo y Mahatta Raml son espacios antiguos reafirmados, el complejo West el Balad-Carrefour, Green Plaza y San Stefano son nuevos centros, pero no por ello carentes de un fuerte simbolismo de centralidad para una parte de la población. Esta centralidad se instaura sobre un conjunto de funciones definitorias de consumismo, ostentación, reproducción social de valores de una nueva clase alta por ser un lugar de encuentro, relaciones sociales y reafirmación de la pertenencia a un determinado sector de la población. La centralidad, lejos de limitarse al clásico concepto de centro geográfico como aglomerado de funciones administrativas, comerciales, residenciales y sociales, adquiere en Alejandría una forma difusa y dibujada en distintos focos de centralidad según sus funciones, temas y miradas humanas.

La división social simbólica de la urbe en Alejandría se caracteriza, además de sus policentralidades segregadoras, por dos aspectos que definen la ciudad neoliberal: el abandono del patrimonio histórico - destrucciónjunto con un proceso que, de modo similar al de gentrificación, actúa para favorecer la inversión privada en el sector inmobiliario - creativa-. La dualidad entre lo "antiguo" y lo "nuevo" se enfatiza en la ciudad neoliberal, primando aquello que dé más ganancia sobre los valores "simplemente" culturales o tradicionales.

\section{Franquicias de comida rápida: el paradigmático simbolismo neoliberal}

Las franquicias de empresas internacionales son un fuerte símbolo de la globalización económica. El poderoso ejemplo del establecimiento de la compañía McDonald's en la Plaza Roja de Moscú se ha convertido en una práctica propia y definitoria de la economía -y no sólo- transnacional. El proceso de "mcdonalización" de la sociedad, concepto propuesto por George Ritzer (1999), ha permitido explicar cómo la estructura organizacional y de marketing de esta cadena estadounidense es aplicable, y así ha ido imponiéndose a distintos ámbitos de la sociedad (desde los supermercados a la educación), valiéndose de algunos de sus mecanismos más eficaces, como son la homogeneización -similares menús en Estados Unidos, China, Malasia o Egipto-, la facilidad de acceso - precios irrisorios, aunque imposibles para 
el mercado local-, la comodidad, la rapidez, la adaptación a los distintos rangos de edades, entre otros.

La construcción cultural de las franquicias neoliberales no es, sin embargo, un "copiar y pegar" desde el país donde surge a aquel país donde se expande, sino que se produce una adaptación al ambiente local, al mismo tiempo que la franquicia adquiere unas connotaciones espaciales específicas. En Egipto, las franquicias de comida rápida, que en la mayoría de los países centrales tienen éxito como un producto barato, son consideradas un lugar para las personas de renta media y alta ya que los precios son similares a los de Europa o Estados Unidos, pero los salarios son mucho más bajos. Sirva de ejemplo el menú de una de estas franquicias neoliberales para entender tal disparidad. En el caso de KFC el precio de los menús oscila entre 30 y 80 libras egipcias. ${ }^{9}$ Tengamos en cuenta la comida egipcia popular, como puede ser un falafel, un ful de habas o un shawarma: los primeros cuestan alrededor de 1.5 libras egipcias, mientras que el último, el shawarma, cuesta en torno a 7 u 8 libras. El contraste de precio es destacadamente diferenciador. ${ }^{10}$ Pongamos también el caso de un menú de McDonald's, quizás incluso más útil para contrastar con la comida local, pues se compara como menú individual. Los precios de una hamburguesa oscilan entre 10 y 12 libras egipcias, es decir, se duplica e incluso triplica el precio en comparación con una ración individual de comida local. ${ }^{11}$ Ésta es una apreciación fundamental para entender el simbolismo espacial de las franquicias en Alejandría, que a continuación analizamos.

Una redundante seña de identidad de la ciudad neoliberal es la presencia de cadenas de empresas globales dispersas no sólo por los lugares donde nacieron, sino también por donde se establecieron posteriormente. Éste es el caso no sólo de McDonald's, sino también de otras cadenas internacionales como Starbucks, Costa Coffee, Domino's Pizza, PizzaHut o KFC. Cabe asimismo señalar que en Egipto han surgido réplicas de cadenas de comida rápida propiamente egipcia, como es el caso de Momen. Esta cadena sirve

9 Cuando escribimos este artículo, el cambio se situaba en 9 libras egipcias por cada dólar estadounidense. A principios de noviembre de 2016 el gobierno egipcio devaluó su moneda, siendo el cambio a inicios de 2017 de 19 libras por cada dólar. Hemos decidido mantener los precios anteriores por la variabilidad actual. Sin embargo, el análisis sigue siendo pertinente, ya que la mayoría de los productos de las franquicias doblaron su precio tras la devaluación.

10 El salario mínimo en el sector público es de 1200 libras egipcias desde 2014 y no existe salario mínimo en el sector privado. A pesar de que no hay datos oficiales, el salario medio en el ámbito urbano se situaría en el rango de 800 a 2000 libras mensuales. Sin embargo, existen millones de personas con trabajos informales e ingresos variables o que dependen de las propinas en el sector servicios.

${ }^{11}$ En la página http://menuegypt.com/menu pueden consultarse los menús de las cadenas de comida rápida más importantes en Egipto. 
comida rápida a unos precios elevados en comparación con la comida que se vende en lugares típicamente locales -los precios de sus menús individuales, como los bocadillos de carne de ternera o de pescado, están entre 25 a 30 libras egipcias-. Momen sería un buen ejemplo de franquicia local neoliberal en Egipto: su comida intenta imitar a la de las franquicias internacionales, pero adaptándose a los gustos egipcios y cumpliendo con el carácter elitista de precios altos de las franquicias internacionales.

Nos ceñimos en este artículo a franquicias del ramo restaurantero y, en concreto, encuadradas en el concepto de comida rápida -fast food-. Esta selección de franquicias globales de comida rápida o cafeterías rápidas -en el caso de Starbucks y Costa Coffee- se fundamenta en tres motivos claves: la comida rápida es unívoca de un momento histórico en el que se prima la rapidez por encima de la calidad o la cultura gastronómica, tal como es la realidad de la ciudad neoliberal; en segundo lugar, por ser la comida una necesidad básica ${ }^{12}$ es representativa y permite explicar antropológicamente la importancia y consecuencias que tiene la implantación de este tipo de franquicias en lugares absolutamente distantes cultural e ideológicamente del lugar donde surgieron; por último, estas franquicias neoliberales, valiéndose de ofrecer un servicio básico, se sitúan espacialmente en lugares estratégicos que impulsan no sólo su visibilidad, sino también su continuidad, convirtiéndose en un icono de la colonización neoliberal económica, cultural y social.

La instauración de lo que hemos llamado franquicias neoliberales no es simplemente un rasgo más de intercambio de bienes dentro del marco de la globalización. En Alejandría, las franquicias neoliberales se encuentran repartidas por determinadas zonas de la ciudad, fundamentalmente en torno a dos tipos de localizaciones. La primera, de significación básicamente social: cercana a los centros consumistas y a los centros sociales y deportivos. En la segunda, la localización está fundamentada no sólo socialmente, sino geográficamente en cuanto a buenas comunicaciones y a la alta cantidad de población que transita alrededor, sea el caso de la Corniche y el centro histórico (Mapa 4 y Fotografías 11 y 12).

Los lugares anteriormente descritos se caracterizan por su centralidad, ya sea geográfica, cultural o económica, y es precisamente este rasgo el que actúa como polo de atracción de las franquicias neoliberales. Este análisis de mercado en cuanto a territorio espacial no es una característica exclusiva

12 Siendo conscientes de que la necesidad es el acto de comer para saciar el hambre, aunque esta necesidad haya evolucionado culturalmente hacia un entorno donde no sólo se busca cumplir una función humana imprescindible, sino que se rodea de diversos elementos culturales (socialización, prestigio, calidad alimentaria...). 


\section{Mapa 4}

Franquicias neoliberales en Alejandría

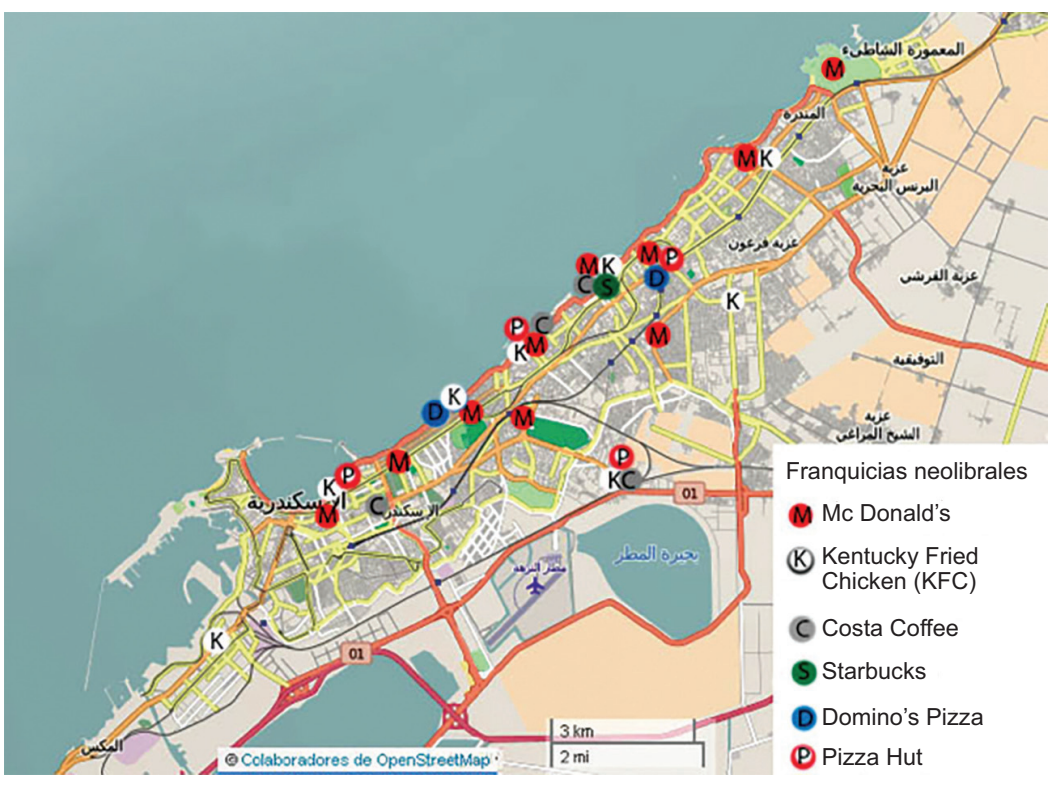

Fuente: Elaboración propia con base en OpenStreetMap.

de empresas globales como KFC o Starbucks, sino una norma elemental de análisis mercantil de la realidad. Sin embargo, esta práctica de implantación de franquicias neoliberales se ajusta, una vez más, a varios de los momentos de destrucción creativa del neoliberalismo urbano de Brenner, Peck y Theodore (2015: 234-235), y en concreto, a dos de los mecanismos del urbanismo neoliberal: uno de ellos, "las transformaciones de la ciudad construida y la forma urbana", y el otro, "el mecanismo de reestructuración de las estrategias de desarrollo territorial". La transformación se produce al crear nuevos espacios de consumo para la élite, intensificando la polarización socioespacial, en este caso entre quienes pueden o no pagar los menús de las franquicias neoliberales. ${ }^{13}$

En segundo lugar, la reestructuración del desarrollo territorial se produce al tener que competir la economía local con una competitiva economía

13 Recordemos que se paga no tanto la comida, sino el prestigio social de poder acceder a tales servicios. 


\section{Fotografía 11}

KFC y Domino's Pizza situados en la Corniche. Buenas comunicaciones y localización estratégica

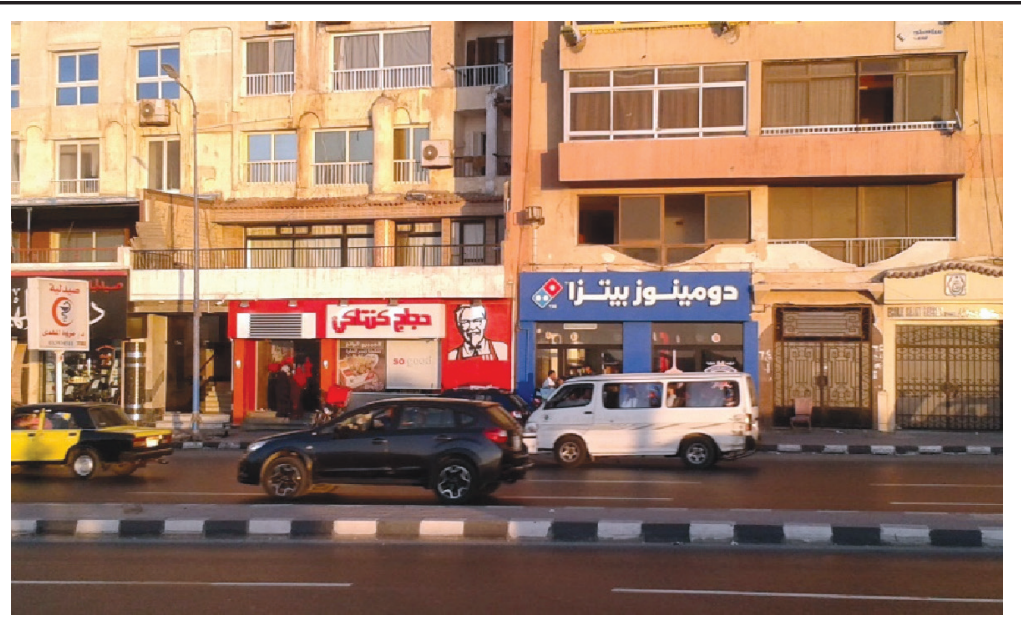

Fuente: Fotografía de los autores.

\section{Fotografía 12}

Costa Café, franquicia en la calle Fuad, en las cercanías de varios centros culturales y el Consulado Español

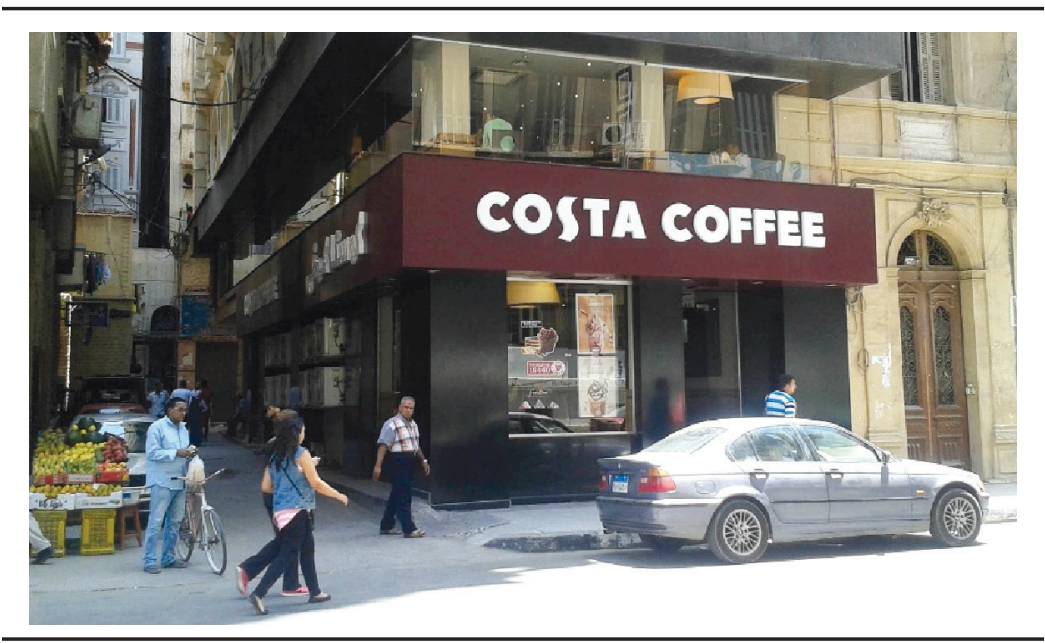

Fuente: Fotografía de los autores.

Estudios Demográficos y Urbanos, vol. 33, núm. 1 (97), 2018, pp. $43-78$ ISSN 0186-7210; e-ISSN 2448-6515; doi: http://dx.doi.org/10.24201/edu.v33i1.1734 
global. Este proceso anterior sería de destrucción-dadas las dificultades para enfrentarse a empresas multinacionales-, completándose la destrucción creativa mediante estrategias locales para implantar franquicias neoliberales en contextos culturales alejados. La franquicia neoliberal en Alejandría no supone un ataque directo a la economía local de comida, teniendo en cuenta sus precios, como se produce en otros lugares de Europa, por ejemplo. En Alejandría, dichas cadenas restauranteras se encuadran dentro del neoliberalismo depredador del que Janoschka (2016) hablaba, por tres motivos fundamentales: son un pivote clave de diferenciación socioeconómica de la población alejandrina, pertenecen al grupo de las empresas de lo que Sami Naïr (2015: 7) llamaba mercantilización del uso de la naturaleza ${ }^{14} \mathrm{y}$, por último, son un símbolo esencial del neoliberalismo, como se explica a continuación.

Adjetivábamos este apartado como el paradigmático simbolismo neoliberal. Las franquicias neoliberales, lejos de ser simplemente una muestra imperiosa del poder interligado político-económico, detentan un enfático poder simbólico a nivel cultural. Los ritos, complejos entramados de símbolos, no se limitan al pasado cultural, aunque se fortalecen con esta tradición. Victor Turner (1967: 19) definía el símbolo como "la unidad más pequeña del ritual que retiene las propiedades específicas de la conducta ritual"; además, completaba su definición con la propuesta por el Concise Oxford Dictionary, que considera el símbolo como un elemento que, por acuerdo general, tipifica o representa una determinada cosa por tener unas características análogas o por asociarse con determinado hecho (Turner, 1967: 19).

El análisis simbólico sirve para valorar la imposición espacial del neoliberalismo porque también éste es un ritual, siendo las franquicias neoliberales uno de sus símbolos más vistosos. Turner (1967: 19) enumeraba una lista de símbolos que observaba en su estudio entre los ndembu: objetos, actividades, relaciones, eventos, gestos y unidades espaciales.

La instauración de franquicias en Alejandría, como en otros lugares fuera de donde nacieron y a pesar de la contextualización y especificidad de cada caso, sigue un patrón similar: se mercantilizan objetos y actividades (en McDonald's los menús suelen venir con regalos para niños, que atraen su atención, y además se organizan pequeños campeonatos), ${ }^{15}$ pero también

14 La amplitud de este tema excede el espacio de este artículo, pero cabe destacarlo por ser un problema actual, aunque no el más grave, al que las ciudades se enfrentan.

15 El más reciente en países como Portugal, donde enmarcado en el campeonato europeo de futbol, se organizó una pequeña liga de futbol infantil. Es decir, como Brenner, Peck y Theodore (2015: 216) remarcaban, "el neoliberalismo realmente existente, al igual que los mercados realmente existentes, son fenómenos ineludiblemente insertos y dependientes de un contexto". 
relaciones (se ha indicado cómo sólo extranjeros, alejandrinos de renta alta o aquellos que persiguen el prestigio del lugar acuden a lugares como Starbucks). La asistencia a franquicias neoliberales para consumir o para estrechar relaciones sociales es un ritual en sí mismo, en una estructura ritual inserta en la propia ritualidad del neoliberalismo y en las unidades espaciales.

Esta serie de elementos que el neoliberalismo urbano utiliza y repite sigue una lógica espacial que lo fortalece. La construcción de una cafetería de Starbucks o un McDonald's en un lugar de centralidad, ya sea en el casco antiguo de Alejandría, en el barrio Smouha o en el barrio Kafr Abdo, en un edificio antiguo o en un centro comercial reciente, lo dota de la eficacia del lugar. Pero también la franquicia neoliberal transforma el entorno donde se localiza y, recurriendo a la clásica dualidad de Levy (citado por Zárate y Rubio, 2007) de continente (morfología urbana) versus contenido (lo social), ambos conceptos se entremezclan y difuminan sus contornos, pues la presencia de una sucursal de KFC puede tender a modificar las actitudes de los habitantes del barrio -al poder optar por consumir un producto no local-, así como las tiñe de una significación social nueva y diferenciadora -los habitantes que frecuentan los establecimientos de franquicias neoliberales en Alejandría no son la mayoría, sino los que pueden pagar por una comida más cara o que acuden a este entorno globalizado buscando adherirse a una cultura externa y contagiarse de su "supuesta" supremacía cultural-. Este fenómeno es bastante recurrente en algunos países periféricos, como Egipto. Es decir, con la presencia de franquicias neoliberales se produce una modificación del hábitat cultural-simbólico.

El neoliberalismo, lejos de ser una simple hegemonía económica, además de sustentarse en el aparato político, consigue establecerse, extenderse y enraizarse sólo a través de la conquista social y cultural del lugar donde se instala. Las franquicias neoliberales son uno de los símbolos del ritual neoliberal por retener, como afirmaba Turner, las propiedades concretas de la conducta ritual, como son la división socioeconómica, la centralidad como eje para establecerse en el espacio urbano, y el poder de atracción que ejerce su globalizada imagen de marketing (Fotografía 13).

\section{Conclusiones}

Alejandría reúne características específicas respecto a otras ciudades egipcias e internacionales. Sin embargo, como hemos descrito, también ejemplifica la problemática de la ciudad en la época neoliberal, donde la división entre los vencedores y perdedores de la globalización neoliberal es cada vez más 


\section{Fotografía 13}

La franquicia McDonald's cuenta con servicio a domicilio en Egipto

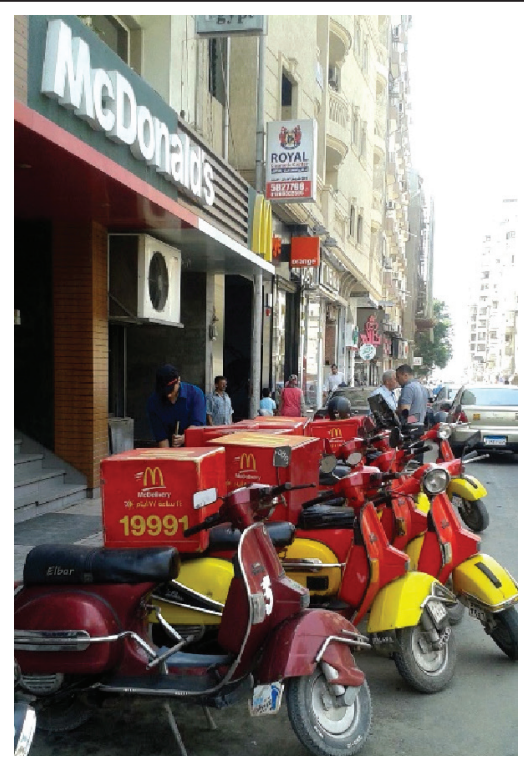

Fuente: Fotografía de los autores.

marcada. La ruptura del contrato social y un darwinismo social creciente son otros de los rasgos visibles en Alejandría. El abandono del Estado de sus responsabilidades básicas en lo que respecta a la planificación, el mantenimiento y la estabilización social supone un riesgo para el desarrollo humano de la población. La necesidad de un Estado equilibrador se hace perentoria y nada hace pensar que sin éste, la situación vaya a cambiar.

Las cuatro características señaladas que definen a Alejandría como una ciudad neoliberal son: la ultraconcentración, el abuso del espacio público, la división de la ciudad entre "ciudad histórico-cultural" y "centros consumistas elitistas" y, por último, el establecimiento de las franquicias internacionales que simbolizan la época neoliberal.

La ultraconcentración se refiere al proceso ampliamente extendido en los países periféricos que combina alta densidad de población, insuficiencia de alojamiento digno a precios asequibles para las clases de bajos recursos, y una gestión ineficiente de la ciudad: tráfico denso, contaminación, inadecuada gestión de residuos y escasas medidas contra las catástrofes naturales previsibles, aspectos que tienen tanto una responsabilidad pública como privada. 
En segundo lugar, se produce en Alejandría el abuso privado del espacio público abandonado por el Estado, pero también por los ciudadanos como lugar propio. El concepto de "invasión pausada" es muy útil para explicar tal problemática: ante el abandono estatal de su responsabilidad social, los ciudadanos, convertidos en simples individuos, se aprovechan de forma privada del espacio público. El Estado no provee ni tampoco controla el proceso; los individuos no contribuyen ni tampoco exigen en un proceso de apropiación neoliberal que conlleva una gestión ineficiente de "lo público".

En tercer lugar, de forma simbólica se produce un traslado del centro histórico colonial británico a los "centros consumistas elitistas" de Carrefour City Center-West el Balad, Green Plaza y San Stefano. El elitismo consumista suburbano prima sobre el elitismo cultural de la época anterior. El caso concreto del barrio de Kafr Abdou es paradigmático porque supone un lugar intermedio entre ambos: se mantiene como barrio de alcurnia pero, a la vez, como centro de consumo elitista a través de restaurantes y cafés caros.

\section{Fotografía 14}

Vendedor callejero de maíz y pareja de enamorados junto al anuncio de la urbanización Alex West

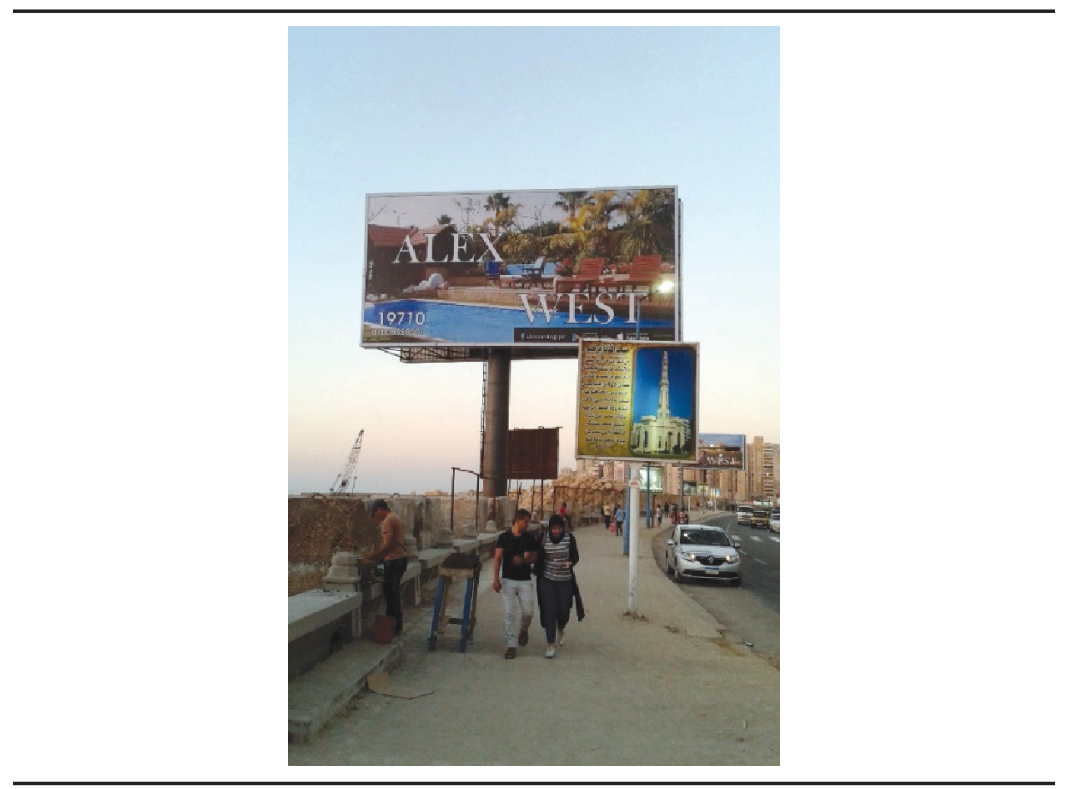

Fuente: Fotografía de los autores.

Estudios Demográficos y Urbanos, vol. 33, núm. 1 (97), 2018, pp. 43-78 ISSN 0186-7210; e-ISSN 2448-6515; doi: http://dx.doi.org/10.24201/edu.v33i1.1734 
Por último, las franquicias neoliberales simbolizan la fortaleza que este fenómeno económico tiene en el proceso urbano. Ante su incapacidad de ofrecerse como comida rápida "barata", son capaces de adaptarse a los países periféricos ofreciendo modernidad y elitismo a precios altos. Se sitúan en los barrios de la clase media y alta, en los lugares de mayor tránsito de personas, en los "centros consumistas elitistas" y, sobre todo, en los lugares con mejores comunicaciones para el vehículo privado.

Para concluir, la división segmentaria del espacio se organiza del siguiente modo: por una parte, la propiedad privada en forma de casas, apartamentos, oficinas y negocios; por otro lado, la propiedad pública, que por ser común se transforma en una "propiedad abstracta" sin organización hacia el bien común. La ausencia de explotación útil comunitaria (como pudieran ser los parques o los centros culturales) conlleva múltiples apropiaciones privadas en perjuicio del bien común. Sin un equilibrio entre estos dos aspectos, la construcción de una ciudad más habitable se hace imposible (Fotografía 14).

\section{Bibliografía}

Abu-Lughod, Janet (1965), "Urbanization in Egypt: Present state and future prospects", Economic Development and Cultural Change, vol. 13, núm. 3, pp. 313343. Recuperado de https://www.jstor.org/stable/1152248?seq=1\#page_scan tab contents

Amin, Galal (2011), Egypt in the era of Hosni Mubarak, 1981-2011, El Cairo, The American University in Cairo Press.

Bayat, Asef (2010), Life as politics. How ordinary people change the Middle East, Amsterdam, Amsterdam University Press.

Bayat, Asef y Eric Denis (2000), "Who is afraid of ashwaiyyat? Urban change and politics in Egypt”, Environment and Urbanization, vol. 12, núm. 2, pp. 185-199. Recuperado de http://journals.sagepub.com/doi/pdf/10.1177/09562478 0001200215

Brenner, Neil, Jamie Peck y Nick Theodore (2015), "Urbanismo neoliberal. La ciudad y el imperio de los mercados", en Observatorio Metropolitano de Madrid, El mercado contra la ciudad. Globalización, gentrificación y políticas urbanas, Madrid, Traficantes de sueños, pp. 211- 243.

CAPMAS (2015), Página oficial de Central Agency for Public Mobilization and Statistics, El Cairo. Recuperado de www.capmas.gob.eg (consultado en julio de 2015).

CAPMAS (2016), Página oficial de Central Agency for Public Mobilization and Statistics, El Cairo. Recuperado de www.capmas.gob.eg (consultado en enero de 2016). 
Carrión, Fernando (2016), “América Latina, las ciudades del mañana las vivimos hoy", conferencia magistral impartida en el posgrado de Urbanismo, UNAM, Ciudad de México, 17 de febrero.

Castells, Manuel (1986), La ciudad y las masas. Sociología de los movimientos sociales urbanos, Madrid, Alianza.

Chaichian, Mohammad A. (1988), "The effects of world capitalist economy on urbanization in Egypt, 1800-1970", International Journal of Middle East Studies, vol. 20, núm. 1, pp. 23-43. Recuperado de https://www.jstor.org/ stable/163584?seq=1\#page_scan_tab_contents

Davis, Kingsley y Hilda Golden (1954), "Urbanization and the development of preindustrial areas", Economic Development and Cultural Change, vol. 3, núm. 1, pp. 6-26. Recuperado de https://www.jstor.org/stable/1151656?seq=1\#page_ scan tab_contents

Elsheshtawy, Yasser (2006), "From Dubai to Cairo: Competing global cities models", en Diane Singerman y Paul Amar (eds.), Cairo cosmopolitan: politics, culture, and urban space in the new globalized Middle East, Cairo, American University in Cairo Press, pp. 235-250.

Hamdan, Gamal (1962), "The pattern of medieval urbanism in the Arab world", Geography, vol. 47, núm. núm. 2, pp. 121-134. Recuperado de https://www. jstor.org/stable/40565373?seq=1\#page_scan_tab_contents

Harvey, David (1977), Urbanismo y desigualdad social, Madrid, Siglo XXI.

Harvey, David (1978), The urban process under capitalism: A framework for analysis, Oxford, Blackwell.

Harvey, David (2007), "Neoliberalism as creative destruction", The Annals of the American Academy of Political and Social Science, vol. 610, núm. 1, pp. 21-44. Recuperado de http://journals.sagepub.com/doi/pdf/10.1177/0002716206296780

Harvey, David (2016), "Pensamiento crítico y teoría del valor," ponencia presentada en el Seminario Internacional "Teoría del valor, comunicación y territorio", Quito, CIESPAL, 23 de enero.

Henderson, Vernon (2002), "Urbanization in developing countries", The World Bank Research Observer, vol. 17, núm. 1, pp. 89-112. Recuperado de https://openk nowledge.worldbank.org/bitstream/handle/10986/16420/766680JRN0WBRO0 0Box374385B00PUBLIC0.pdf?sequence=1\&isAllowed=y

Janoschka, Michael (2016), "Ciudades contestadas, ciudades imaginadas", ponencia presentada en las Jornadas “Arte e política reloaded. O direito á cidade”, Lisboa, ISCTE-IUL/ CRIA, 5 a 8 de junio.

La Nación (2006), "David Harvey: El neoliberalismo sigue vivo en la Argentina", La Nación, Buenos Aires, 16 de agosto.

Myrdal, Gunnar (1979), The challenge of world poverty, Londres, Penguin Press.

Naciones Unidas (2015), "Population of capital cities and cities of 100000 inhabitants: Latest available year, 1995-2014. Demographic yearbook", informe, Washington, Department of Economic and Social Affairs.

Naïr, Sami (2015), "La educación como fundamento del cambio de la vinculación 
existente entre el ser humano y el medio ambiente", ponencia presentada en el XI Congreso Nacional de Periodismo Ambiental "¿Importa el medio ambiente a nuestros políticos?”, Madrid, APIA, 25 de noviembre.

Pallini, Cristina (2005), "The revival of Islamic architecture in Egypt: Some notes on the Italian contribution (1898-1953)", ponencia presentada en CAA 94 ${ }^{\text {th }}$ Annual Conference, Boston, 22 a 25 de febrero.

Pallini, Cristina (2010), "Geographic theatres, port landscapes and architecture in the Eastern Mediterranean: Salonica, Alexandria, İzmir”, en Biray Kolluoğlu y Meltem Toksöz (eds.), The cities of the Mediterranean from the Ottomans to the present day, Londres, Tauris, pp. 61-77.

Pallini, Cristina (2013), "Staging the past and the future along Alexandria's Corniche", ponencia presentada en "Conference for Changing Cities: Spatial, morphological, formal and socio-economic dimensions", Skiathos Island, 18 a 21 de junio.

Paris, Mario (2012), "De los centros urbanos consolidados a los lugares de centralidad: una propuesta metodológica para su estudio", Ciudades vol. 16, núm. 1, pp. 47-69. Recuperado de http://uvadoc.uva.es/bitstream/10324/10345/1/ CIUDADES-2013-16-DELOSCENTROS.pdf

Pelletier, Jean y Charles Delfante (1997), Ciudades e urbanismo no mundo, Lisboa, Piaget.

Ritzer, George (1999), La mcdonalización de la sociedad, Madrid, Popular.

Rodríguez, Alfredo y Paula Rodríguez (2009), Santiago, una ciudad neoliberal, Quito, OLACCHI.

Rodríguez, Alfredo y Paula Rodríguez (2012), "Santiago, una ciudad neoliberal”, Carajillo de la Ciudad, vol. 4, Barcelona, Programa en Gestión de la Ciudad. Recuperado de http://www.cafedelasciudades.com.ar/carajillo/13_art3.htm

Rossi, Aldo (1971), La arquitectura de la ciudad, Barcelona, Gustavo Gili.

Rubio Benito, María Teresa y Manuel Antonio Zárate (2007), Geografía humana. Sociedad, Economía y Territorio, Madrid, Universitaria Ramón Areces.

Saad, E. M. Ibrahim (1975), "Over-urbanization and under-urbanism: The case of the Arab world", International Journal of Middle East Studies, vol. 6, núm. 1, pp. 29-45. Recuperado de https://www.jstor.org/stable/162733?seq=1\#page scan_tab_contents

Santillán Cornejo, Alfredo (2015), "Imaginarios urbanos y segregación socioespacial. Un estudio de caso sobre Quito", Cuadernos de Vivienda y Urbanismo, vol. 8, núm. 16, pp. 246-263. Recuperado de http://revistas.javeriana.edu.co/index.php/ cvyu/article/view/14682/0

Silva, Armando (2004), Imaginarios urbanos: hacia el desarrollo de un urbanismo desde los ciudadanos, Bogotá, Convenio Andrés Bello (Metodología).

Singerman, Diane y Paul Amar (2006), Cairo cosmopolitan: Politics, culture and urban space in the new globalized Middle East, El Cairo, The American University in Cairo Press.

Smith, Neil (2012), La nueva frontera urbana. Ciudad revanchista y gentrificación, Madrid, Traficantes de Sueños. 
Soja, Edward W. (2008), Postmetrópolis. Estudios críticos sobre las ciudades y las regiones, Madrid, Traficantes de Sueños.

Tarbush, Nada (2012), “Cairo 2050. Urban dream or modernist delusion?”, Journal of International Affairs, vol. 65, núm. 2, pp. 171-186. Recuperado de https://jia. sipa.columbia.edu/cairo-2050-urban-dream-or-modernist-delusion

Topalov, Christian (2006), La urbanización capitalista. Algunos elementos para su análisis, Buenos Aires, Universidad de Buenos Aires.

Turner, Victor (1967), The forest of symbols, Ithaca, Nueva York, Cornell University Press.

Velasco, Honorio (2007), Cuerpo y espacio. Símbolos, metáforas, representación y expresividad en las culturas, Madrid, Universitaria Ramón Areces.

\section{Acerca de los autores}

María José Vizcaíno Pina es trabajadora social por la Universidad de Murcia con el trabajo final de investigación "Consumo de drogas en España desde los años ochenta. Causas para el consumo". Es antropóloga social y cultural por la Universidad Nacional de Educación a Distancia (UNED); y maestra en Estudios Latinoamericanos por el Instituto de Iberoamérica de la Universidad de Salamanca, donde elaboró el trabajo final "Geografía urbana del poder en Lima. Una perspectiva simbólica". Es docente de formación profesional para el empleo con la propuesta de curso "Elaboración de productos para personas con intolerancias y alergias alimentarias". Diseñó el curso en línea "Alimentación. Hacia una verdadera conciencia ecológica" (2014); y elaboró el documento "The Help. Una mirada desde la antropología simbólica", presentado en las Jornadas de Investigación "Género y producción del espacio", Barcelona, 25 a 27 de noviembre de 2015. Está interesada en la investigación social sobre antropología urbana, género, metodologías alternativas de educación y antropología de la comida. Actualmente reside en Portugal, donde escribe relatos breves e investiga sobre la manipulación del coaching empresarial.

Pedro Antonio Vizcaíno Pina es doctorando en Sociología en la Universidad de Alejandría, Egipto, con una beca Erasmus Mundus otorgada por la Comisión Europea. Tiene una maestría en Cultura de Paz, Conflictos, Derechos Humanos por la Universidad de Granada, en la que elaboró la tesina "Las revueltas de Túnez y Egipto: simbolismo y noviolencia". Es licenciado en Antropología Social y Cultural por la Universidad Nacional de Educación a Distancia (UNED) y en Filología Árabe por la Universidad de Granada. Está interesado en temas que giran en torno a la gestión del poder, el discur- 
so político y el control sociopolítico; la movilización social; el urbanismo y las desigualdades; y la democratización y la represión. Es autor del capítulo: "La recuperación de espacios públicos como símbolo de poder. El movimiento 15M", en Danú Fabre y Carmen Egea (coords.), La indignación. Un desencanto en privado y un descontento en lo público, Granada, Universidad de Granada / Universidad Veracruzana, 2013. Actualmente está terminando su periodo de trabajo de campo en Alejandría, y está inmerso en la redacción de tu tesis doctoral "Discurso hegemónico y contrahegemónico en Egipto durante el periodo 2000-2016".

Fecha de recepción: 6 de marzo de 2017.

Fecha de aceptación: 9 de junio de 2017. 